\title{
Una nueva evaluación de la Plaza de los Peregrinos de Pachacamac: Aportes de la primera campaña 2003 del Proyecto Arqueólogico Pachacamac
}

Une nouvelle évaluation de la Place des Pèlerins de Pachacamac. Apport de la première campagne 2003 du Projet Archéologique Pachacamac

A New Assessment of the Pilgrims' Plaza at Pachacamac: Significance of the Results of the First Season (2003) of the Pachacamac Archaeological Project

Izumi Shimada, Rafael Segura Llanos, María Rostworowski De Diez Canseco y Hirokatsu Watanabe

\section{OpenEdition} Journals

Edición electrónica

URL: http://journals.openedition.org/bifea/5106

DOI: 10.4000/bifea.5106

ISSN: 2076-5827

\section{Editor}

Institut Français d'Études Andines

\section{Edición impresa}

Fecha de publicación: 1 diciembre 2004

Paginación: 507-538

ISSN: 0303-7495

Referencia electrónica

Izumi Shimada, Rafael Segura Llanos, María Rostworowski De Diez Canseco y Hirokatsu Watanabe, "Una nueva evaluación de la Plaza de los Peregrinos de Pachacamac: Aportes de la primera campaña 2003 del Proyecto Arqueólogico Pachacamac », Bulletin de l'Institut français d'études andines [En línea], 33 (3) | 2004, Publicado el 08 diciembre 2004, consultado el 02 diciembre 2020. URL : http:// journals.openedition.org/bifea/5106; DOI : https://doi.org/10.4000/bifea.5106

Les contenus du Bulletin de l'Institut français d'études andines sont mis à disposition selon les termes de la licence Creative Commons Attribution - Pas d'Utilisation Commerciale - Pas de Modification 4.0 International. 
Bull. Inst. fr. études andines

2004, 33 (3): 507-538

\title{
UNA NUEVA EVALUACIÓN DE LA PLAZA DE LOS PEREGRINOS DE PACHACAMAC:
}

\author{
Aportes de la primera campaña 2003 del Proyecto \\ Arqueólogico Pachacamac
}

\author{
Izumi SHIMADA*, Rafael SEGURA LLANOS**, María ROSTWOROWSKI \\ DE DIEZ CANSECO ${ }^{* * * *}$, Hirokatsu WATANABE H.**** $^{*}$
}

\section{Resumen}

Durante los meses de junio a agosto del año 2003, el Proyecto Arqueológico Pachacamac, bajo la co-dirección de Izumi Shimada, Rafael Segura Llanos y María Rostworowski de Diez Canseco, llevó a cabo su primera temporada de campo, en el marco de un programa de investigaciones de largo plazo. Este proyecto, de carácter interdisciplinario e internacional, tiene como principal orientación el estudio de los fundamentos sociales y el contexto natural del afamado sitio de Pachacamac. Uno de los objetivos específicos de nuestros trabajos durante el año 2003 fue definir la localización y extensión de las áreas residenciales correspondientes a diferentes periodos de tiempo, mediante prospecciones con un radar de penetración de suelos y excavaciones de sondeo. En esta oportunidad, presentamos los resultados más importantes de tales intervenciones en la Plaza de Los Peregrinos, en un sector próximo al llamado Ushnu incaico. Entre los diversos niveles ocupacionales Ychsma detectados, nos hallamado notablemente la atención algunos asociados con una repetida veneración y entierro de cántaros, resaltando que cada una de estas vasijas fue hallada dentro de construcciones de adobe o cercaduras de piedra cuidadosamente construidas. En general, consideramos que los datos obtenidos abren una nueva oportunidad para revisar nuestra actual concepción de la zona considerada sagrada, a la luz de 1) el hallazgo de ofrendas diversas, densas y superpuestas asociadas con estructuras de quincha y adobe, igualmente superpuestas pero espacialmente diferenciadas; y 2) el registro de una serie de cambios importantes en la naturaleza del uso del área a través del tiempo.

Palabras claves: Pachacamac, Plaza de los Peregrinos, ofrendas.

*Izumi Shimada: Southern Illinois University at Carbondale. E-mail:ishimada@ siu.edu

** Rafael Segura: Instituto Riva Agüero, Pontificia Universidad Católica del Perú. E-Mail: rsegura@pucp.edu.pe

**** María Rostworowski: Instituto de Estudios Peruanos. E-mail: iepedit@iep.org.pe

***** Hirokatsu Watanabe: Terra Information Technology, Yokohama, Japon. E-mail: gsrhw942@peach.ocn.ne.jp 


\title{
UNE NOUVELLE ÉVALUATION DE LA PLACE DES PÈLERINS DE PACHACAMAC. APPORT DE LA PREMIËRE CAMPAGNE 2003 DU PROJET ARCHÉOLOGIQUE PACHACAMAC
}

\section{Résumé}

Entre les mois de juin et août 2003, le Projet Archéologique Pachacamac, co-dirigé par Izumi Shimada, Rafael Segura Llanos et María Rostworowski de Diez Canseco, a mené sa première campagne de terrain dans le cadre d'un programme de recherche à long terme. Ce projet interdisciplinaire et international a comme objectif principal l'étude des fondations sociales et du contexte naturel du celèbre site de Pachacamac. L'un des objectifs spécifiques de nos travaux en 2003 a été de définir la localisation et l'extension des zones résidentielles au cours du temps, ce grâce a un radar de pénétration des sols et à des fouilles de sondage. Dans cet essai, nous présentons les résultats les plus importants de ces interventions sur la Place des Pèlerins, plus précisement un secteur proche de l'Ushnu inca. Parmi les divers niveaux d'occupation Ychsma qui ont été détecté, certains ont plus particulièrement attiré notre attention, car ils sont associés à des épisodes récurrents de vénération de jarres en céramique, chacune insérée dans des constructions d'adobes ou des enceintes en pierres soigneusement élaborées.

En termes généraux, il nous paraît que les données obtenues représentent une opportunité nouvelle de reviser nos conceptions actuelles de la zone considérée comme sacrée, à la lumière de 1) la découverte de diverses offrandes, denses et superposées, associées à des structures en canne de joncs et adobes, également superposées mais spatialement differenciées; et 2) la manifestation d'une série de changements importants dans la nature de l'utilisation de la zone au cours du temps.

Mots clés Pachacamac, Place de Pèlerins, offrandes.

\section{A NEW ASSESSMENT OF THE PILGRIMS' PLAZA AT PACHACAMAC: SIGNIFICANCE OF THE RESULTS OF THE FIRST SEASON (2003) OF THE PACHACAMAC ARCHAEOLOGICAL PROJECT}

\begin{abstract}
During the months of July and August of 2003, the Pachacamac Archaeological Project, under the co-direction of Izumi Shimada, Rafael Segura, and Marí9a Rostworowski de Diez Canseco, conducted its first season of what is envisioned as long-term fieldwork. This project with its interdisciplinary and international character has the principal objective of elucidating the social foundations and environmental context of the famed site of Pachacamac. One of the specific aims of our fieldwork in 2003 was to define the location and extent of residential areas corresponding to different time periods by means of ground-penetrating radar survey and related test excavations. In this paper, we present the salient results of this fieldwork in the area of the Pilgrims' Plaza close to the so-called Incaic'ushnu. Notable among the various documented Ychsma occupational levels are those with indications of repeated "cántaro burials and veneration"; in most cases each vessels was placed inside a carefully built adobe or stone enclosure. In general, the data we collected force us to reassess the existing conception of this "sacred zone" in light of (1) the discovery of numerous, dense and superimposed offerings of mundane items associated with quincha and adobe structures, that are equally superimposed but spatially differentiated, and (2) the documentation of a series of important changes over time in the nature of the use of the zone.
\end{abstract}

key words: Pachacamac, Pilgrims' Plaza, offerings. 


\section{ORIENTACIÓN GENERAL DE NUESTRAS INVESTIGACIONES}

No es ninguna novedad decir que Pachacamac (Fig. 1) es uno de los sitios arqueológicos más importantes y conocidos del Perú. Su extensión, su cercanía a Lima y la temprana atención que recibió de los conquistadores europeos desde la visita hecha por Hernando Pizarro en enero de 1533 (Estete, 1985[1534]) han contribuido sin duda alguna a su especial publicidad. Tampocoes inusual conferirle a este sitio un carácter profundamente ceremonial, como espacio físico donde alguna vez residieron deidades andinas que formulaban oráculos de importancia pan-regional. De hecho, pocos podrían negar que existe la creencia, tan extendida como tácita, de que se cuenta con una buena cantidad de datos y una cada vez mejor comprensión de los procesos culturales ocurridos en este sitio. No es así sin embargo. En verdad, la realidad se dibuja de otra manera, especialmente cuando comparamos los datos arqueológicos con aquellos etnohistóricos, y cuando nos enteramos de cuánto la arqueología ha descubierto en centros similares en otras partes del mundo. Pensamos por ello que, a pesar de los esfuerzos de muchos, aún necesitamos conocimientos firmes sobre una serie de aspectos fundamentales que nos permitan avanzar en la comprensión de Pachacamac y de sus posibles instituciones asociadas.

La creencia de que conocemos bien Pachacamac parecería tener sentido cuando miramos hacia atrás, y nos percatamos de la larga sucesión de investigaciones arqueológicas de campo conducidas en el sitio desde la pionera investigación realizada por Max Uhle en 1896 (Uhle, 1903; véase Cornejo, 2000; Daggett, 1988; Eeckhout, 1999; 2003; Shimada, 1991; en prensa, para una discusión sumaria del trabajo conducido en el sitio y en sus alrededores). Sin embargo, exceptuando el trabajo del arqueólogo alemán y de algunos otros (en particular el Proyecto Ychsma que empezó sus trabajos de campo en Pachacamac en 1999), no creemos caer ni en exageraciones ni en omisiones cuando decimos que la mayoría de tales intervenciones arqueológicas han sido publicadas de manera poco satisfactoria, o han tenido una limitada orientación, escala y duración de investigación que no se condice con la complejidad del sitio. Como todos sabemos, en el pasado varios proyectos de investigación se focalizaron en zonas de alta sensibilidad y complejidad arqueológica como los templos más representativos dentro del área sagrada. Los aportes de estos proyectos han sido sustantivos desde una perspectiva que ha privilegiado tales áreas ceremoniales y monumentales. Sin embargo, casi veinte años atrás Duccio Bonavia ya llamaba la atención acerca del estado de nuestros conocimientos científicos en Pachacamac, al lamentar que

"It is a great pity that work has been concentrated in a single sector [I] of Pachacamac, while the rest remains covered by sand, partly destroyed forever, and now spoiled by poorly conceived reconstructions." (1) (Bonavia, 1985: 137; véase también Shimada, 1991: LV).

Creemos que tales afirmaciones aún mantienen su innegable actualidad. Más recientemente Peter Kaulicke (2000: 313) también ha expresado un sentimiento

(1) "Es una gran pena que el trabajo se haya concentrado solo en un único sector (I) en Pachacamac, mientras que el resto se mantiene constantemente cubierto por la arena, y ahora perjudicado por reconstrucciones pobremente concebidas" (traducción de los autores). 

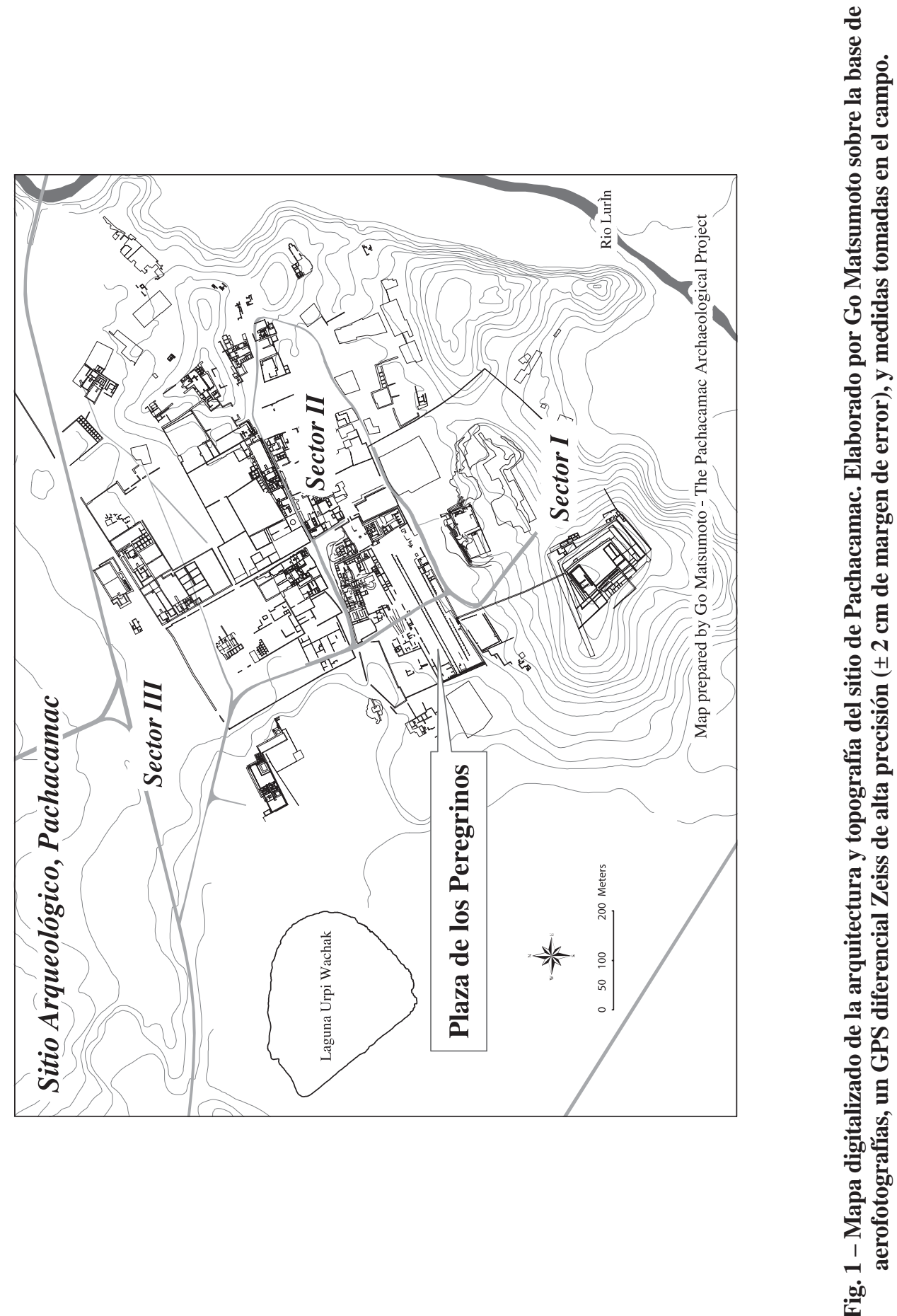
parecido con relación al impacto de la intrusión Huari sobre la costa central, al sostener que

"Se requiere investigaciones más acordes con la problemática específica antes de poder proponer hipótesis alternativas dentro de un contexto social mayor."

Considerando que aún queda mucho por elucidar en torno al contexto social y a los procesos de cambio cultural en Pachacamac, es indudable que esta afirmación es igualmente aplicable al sitio. Consecuentemente, recogiendo estas apreciaciones, se impone un enfoque complementario, uno que asuma en su práctica concreta de investigación la concepción del sitio como una totalidad con múltiples componentes dinámicos e integrados, y que se interese en su composición, organización y dinámica social.

Nuestro proyecto intenta contribuir al conocimiento de Pachacamac adentrándose precisamente desde este lado del problema, preguntándose por los fundamentos sociales que permitieron la notable resiliencia (2) y prolongada duración del sitio a través de más de 1000 años de historia, lapso en el que sobrevino una serie de cambios políticos de envergadura y de alteraciones medioambientales. Nuestro enfoque parte de ciertas preocupaciones elementales, tales como quiénes vivieron en el sitio y qué rol cumplieron; en precisar si Pachacamac fue, en algún momento de su historia, un sitio ceremonial vacío; en cómo sus residentes aseguraron su subsistencia; o en esclarecer si las variaciones en la extensión física del sitio y sus posibles significados extra-locales estuvieron relacionados con condiciones medioambientales particulares. Este último punto es pertinente, ya que nos preguntamos sobre el origen de la concepción de Pachacamac como una deidad que incorporó fuerzas antitéticas de creación y destrucción.

\section{LA TEMPORADA 2003: OBJETIVOS ESPECÍFICOS Y METODOLOGÍA DE TRABAJO DE CAMPO}

Ya que los trabajos del 2003 fueron nuestra primera temporada en el sitio, hemos buscado establecer un sondeo básico para un examen más seguro de las líneas de investigación que se abrirán en el futuro.

Nuestro primer objetivo de campo fue iniciar un proceso de localización de las posibles áreas residenciales pertenecientes a diferentes periodos de tiempo en el sitio. Para ello venimos empleando un Radar de Penetración de Suelos (Fig. 2) y excavaciones de prueba complementarias. Desde nuestro punto de vista, las prospecciones con un radar de este tipo y las excavaciones de prueba concomitantes conforman una estrategia de costo efectivo. El radar permite una rápida detección no destructiva de contextos y elementos enterrados bajo grandes áreas, permitiendo identificar puntos concretos de excavación sin necesidad de realizar excavaciones exploratorias demasiado extensas o diversas sin seguridad de éxito (Clark, 1996; Conyers, 2000; Conyer \& Goodman, 1997). Se trata pues de un instrumento ideal para sitios grandes y complejos como

(2) "Resiliencia" es un término que en mecánica refiere a la resistencia de los cuerpos a la rotura por choque. En este caso lo usamos para referirnos a la capacidad de una institución para adecuarse a las diversas circunstancias históricas que le toca enfrentar. 


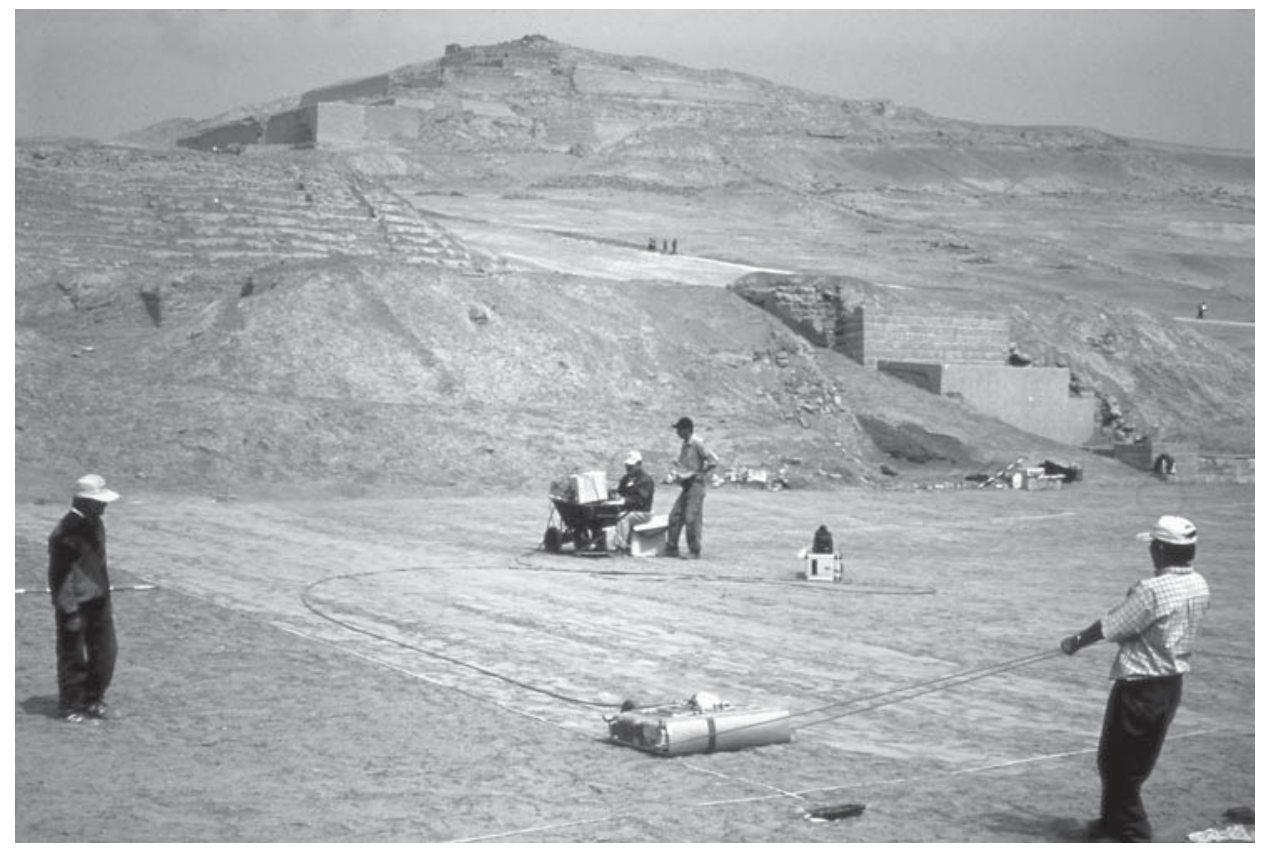

Fig. 2 - Vista panorámica de la prospección con radar (GPR) en el sector oriental (frente de la plataforma del ushnu incaico) de la Plaza de Los Peregrinos. Foto por Izumi Shimada.

Pachacamac, donde los estratos secos y relativamente homogéneos permiten la detección de rasgos ubicados hasta 7 u 8 m debajo de la superficie actual.

Nuestro segundo objetivo consiste en establecer una historia medioambiental integral de Pachacamac y su zona circundante. Para ello venimos obteniendo y examinando una serie de muestras profundas de sedimentos provenientes de la Laguna de Urpay Wachak y de otros puquios antiguos. Es de esperar que las muestras de sedimentos proporcionen polen de la vegetación local, organismos lacustres y sedimentos intermitentes depositados en patrones que puedan atestiguar variaciones anómalas en el registro hídrico. Tales contenidos y su estratificación son cruciales para nuestra investigación. Cabe precisar a este respecto nuestra especial atención al análisis de diatomeas, debido a su gran potencial para la reconstrucción medioambiental. Como se sabe, las diatomeas son organismos unicelulares con altos contenidos de sílica, notablemente sensibles a los cambios medioambientales en razón de sus cortos periodos de vida. En muestras estratificadas las diatomeas pueden convertirse en indicadores plausibles de los cambios drásticos ocurridos en el clima, la humedad, la percolación del suelo, y la calidad de tierra y agua (Denys \& De Wolf, 1999; Juggins \& Cameron, 1999). Por las características del presente ensayo, este segundo objetivo y los trabajos y resultados correspondientes no serán desarrollados aquí. 


\section{ALGUNOS RESULTADOS DE NUESTRO TRABAJO DECAMPOENLA PLAZA DE LOS PEREGRINOS}

Como se verá enseguida, tanto los trabajos de prospección con radar como de excavación en la Plaza de Los Peregrinos nos han proporcionado evidencias reveladoramente útiles para empezar a captar la naturaleza y los cambios ocupacionales y de uso de esta parte de Pachacamac.

\section{1. Prospección con radar}

Dentro del marco de nuestras prospecciones con radar, la plaza inca llamada Plaza de Los Peregrinos (Fig. 3) fue sin duda centro de nuestra especial atención. Dicha plaza, un área rectangular de aproximadamente 65 × 320 m está flanqueda en su lado sur por una plataforma de adobes que contiene una estructura denominada Ushnu, un elemento arquitectónico que constituyó uno de los símbolos físicos más importantes de la ideología inca (Hyslop, 1990: 259). Desde luego, el Ushnu no fue construido en cualquier parte; de hecho se emplaza en una zona altamente sacralizada con antecedentes evidentes (próximo al Templo Pintado de Pachacamac, Templo Viejo de Pachacamac, cementerios como el excavado por Uhle, etc.).

La prospección con radar y la excavación exploratoria desarrollada aquí buscaron examinar la hipótesis de que la Plaza de Los Peregrinos fue el resultado de una reconfiguración inca de gran escala del paisaje sagrado, lo que implicó el entierro de muchas construcciones de periodos anteriores, incluyendo los del Horizonte Medio y el Periodo Intermedio Temprano ( $c f$. Hyslop, 1990: 258-259). Como se verá a continuación, el radar viene proporcionando evidencia que apoya esta hipótesis.

Nuestras prospecciones señalan cierto tratamiento diferente entre las mitades oeste y este de la plaza. En la mitad oeste se ha podido reconocer, básica y preliminarmente, los dos siguientes elementos arquitectónicos (Fig. 4) :

1) Un conjunto de plataformas pequeñas con aparentes cámaras centrales, generalmente ubicadas a aproximadamente 1,5 a 3,0 m debajo de la superficie actual y en la parte sur de este lado de la plaza ("1" en la parte inferior de Fig. 4). Por sus dimensiones consideramos que podrían tratarse de plataformas ceremoniales o estructuras funerarias.

2) Una serie de construcciones, posiblemente de adobes, de función indeterminada a una profundidad aproximada de 2,0 a 4,0 m debajo del superficie actual ("2" en la parte inferior de Fig. 4).

Entre tanto, los hallazgos de la mitad este de la plaza parecen ser más densos y algo diferentes. En este caso tenemos (Fig. 4):

1. Un área adyacente a la base oriental de la plataforma del Ushnu inca. La intensidad y el patrón de señales del radar reproducidas en el monitor conducen a pensar que se trataría de un cementerio con un mínimo de cuatros fosas o cámaras funerarias ubicadas a una profundidad aproximada de 2,0 a 4,0 m debajo del superficie actual ("1" en la parte superior de Fig. 4).

2. Una serie de construcciones relativamente pequeñas (circa 10 m de lado) con subdivisiones internas que corresponderían a residencias o talleres a 


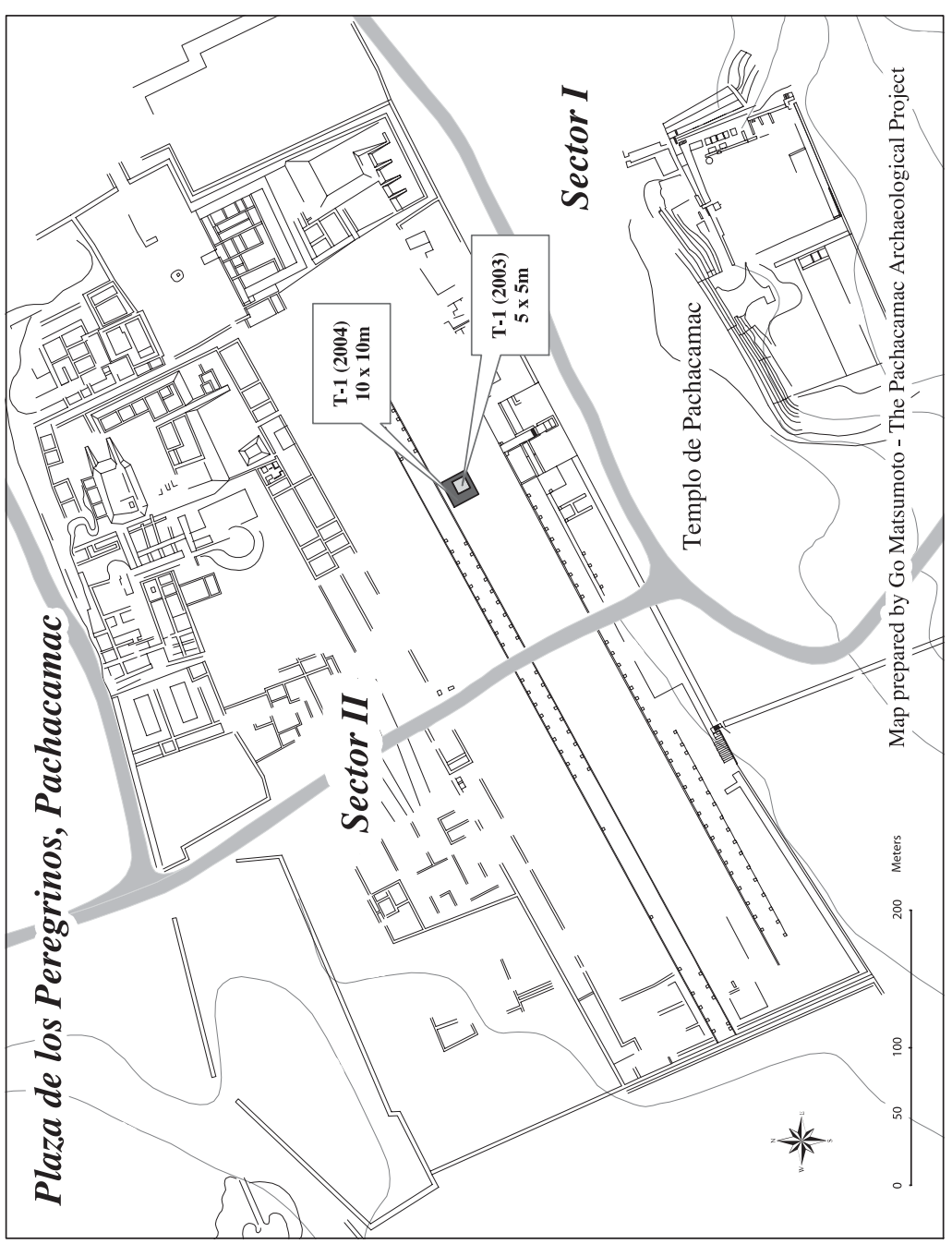

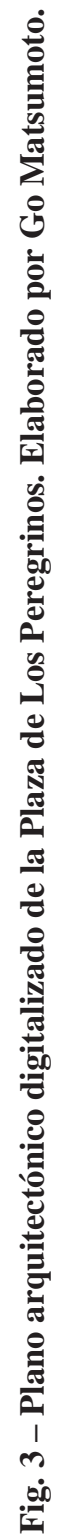




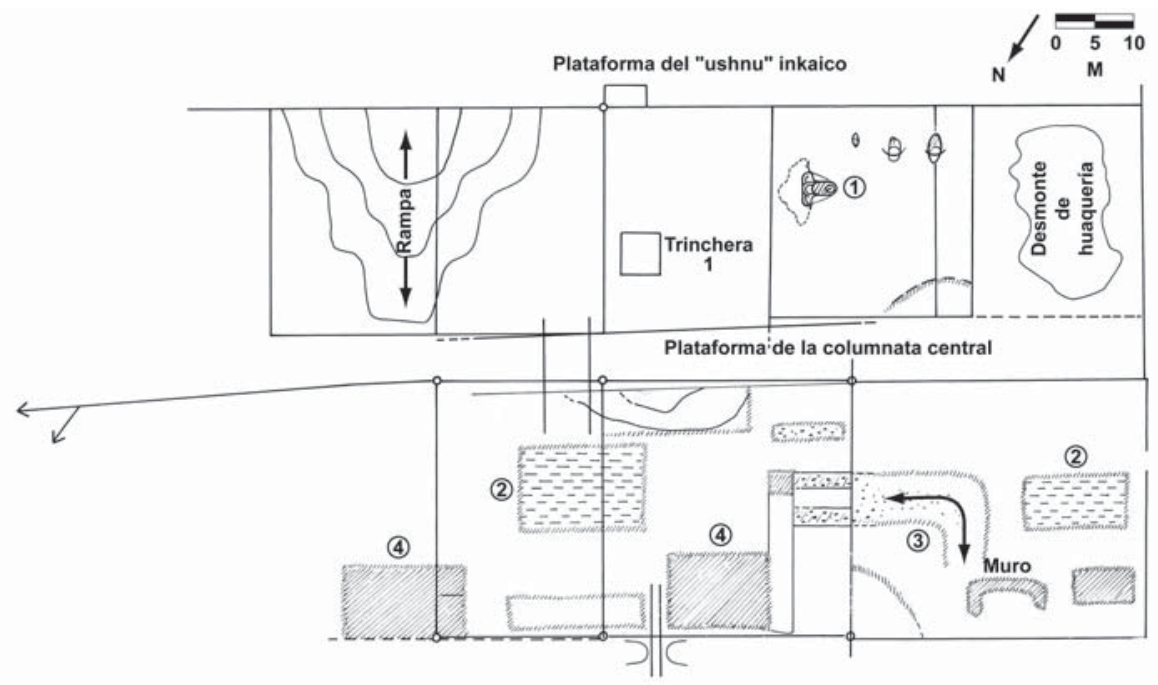

Parte Oriental, Plaza de los Perigrinos

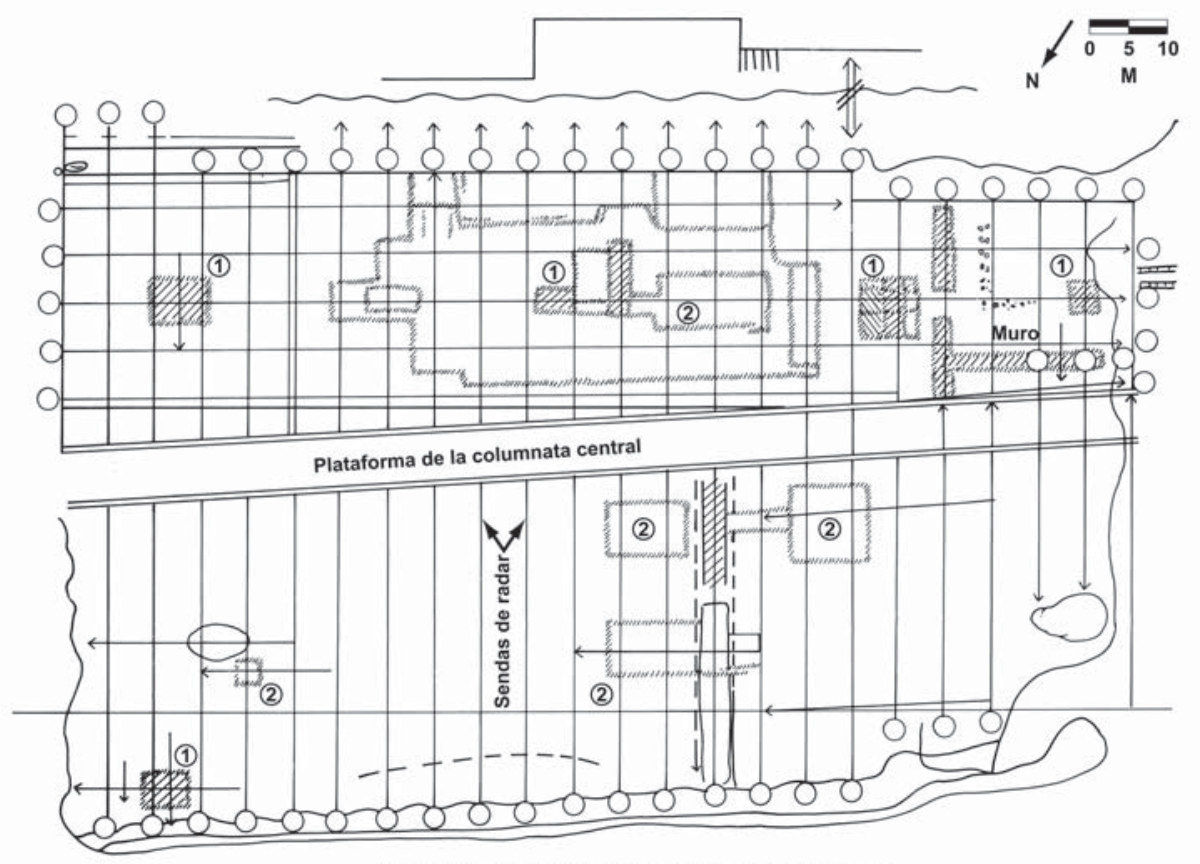

Parte Occidental, Plaza de los Perigrinos

Fig. 4 - Dibujo esquemático de los diferentes rasgos detectados por la prospección con radar (GPR) en los sectores oriental y occidental de la Plaza de Los Peregrinos. Dibujado por Hirokatsu Watanabe. 
aproximadamente 1,5 a 3,0 m debajo del superficie actual (“2” en la parte superior de Fig. 4). Las señales del radar sugieren que sobre estas estructuras se superponen varias capas con alto contenido orgánico.

3. Un espacio abierto pero estrecho en la parte central de este lado de la plaza, que por oposición a las estructuras sólidas laterales podría corresponder a un corredor ("3" en la parte superior de Fig. 4).

4. Diversas construcciones (posiblemente de adobes) diseminadas debajo de la plaza (a una profundidad aproximada de 1,5 a 3,5 m debajo del superficie actual) cuyo carácter aún es indeterminado ("4" en la parte superior de Fig. 4).

5. Hacia la esquina sureste de nuestra trinchera 1 (véase más adelante), las señales del radar y la inclinación del terreno indicaron la existencia de una rampa que conecta con un posible patio hundido ubicado en el lado este, exactamente frente a la porción central de la plataforma del Ushnu inca. Esta posible rampa parece hallarse a 2 m debajo de la superficie. Se deduce por tanto la existencia de construcciones ubicadas debajo de dicha plataforma que pudieron haber sido parte de un acceso central al frontis del Templo de Pachacamac, actualmente oculto por las construcciones posteriores.

6. Una serie de construcciones (próximos a los $4 \mathrm{~m}$ de profundidad con relación a la superficie actual) subyacentes a la calzada con borde de piedra que atraviesa longitudinalmente la plaza (de suroeste a noreste). Como sabemos esta calzada sustentó una fila de pilastras de adobe.

De acuerdo a lo expuesto, podemos señalar que el radar indicó que la plaza esconde muchas construcciones pre-incas, quizás de diferente naturaleza, en profundidades que van de 1 a 6 ó 7 m debajo de la superficie. En nuestra opinión, es bastante claro que el acceso y la organización arquitectónica alrededor y delante del Templo de Pachacamac y del Templo Viejo de Pachacamac fueron sustantivamente diferentes de lo que se observa hoy, existiendo la posibilidad de que existan construcciones que pasan debajo de la plataforma del Ushnu y que llegan al pie del Templo de Pachacamac.

\section{2. Excavación de la trinchera 1}

Durante el año 2003 se abrieron cuatro trincheras en diferentes sectores del sitio (Shimada et al., 2003). Una de ellas, la trinchera 1 de 5 x 5 m (Fig. 5), fue localizada en la Plaza de Los Peregrinos basada en los datos del radar y en las relaciones espaciales entre el Ushnu inca y el templo de Pachacamac. Las señales de microondas indicaron la presencia de depósitos culturales estratificados de apreciable densidad y profundidad (hasta 6 ó 7 m debajo de la superficie) frente aUshnu mencionado. Consecuentemente, la trinchera 1 fue establecida exactamente sobre este punto a fin de definir la naturaleza de la ocupación pre-inca a través de un considerable espacio de tiempo.

Aunque prevenidos en cierto modo por las señales del radar, debemos decir que nuestra excavación solo alcanzó una profundidad de 1,8 m debajo de la superficie, pues la secuencia ocupacional y depósitos culturales asociados resultaron ser algo más complejos de lo esperado. Hemos documentado 31 pisos sin contar las numerosas 


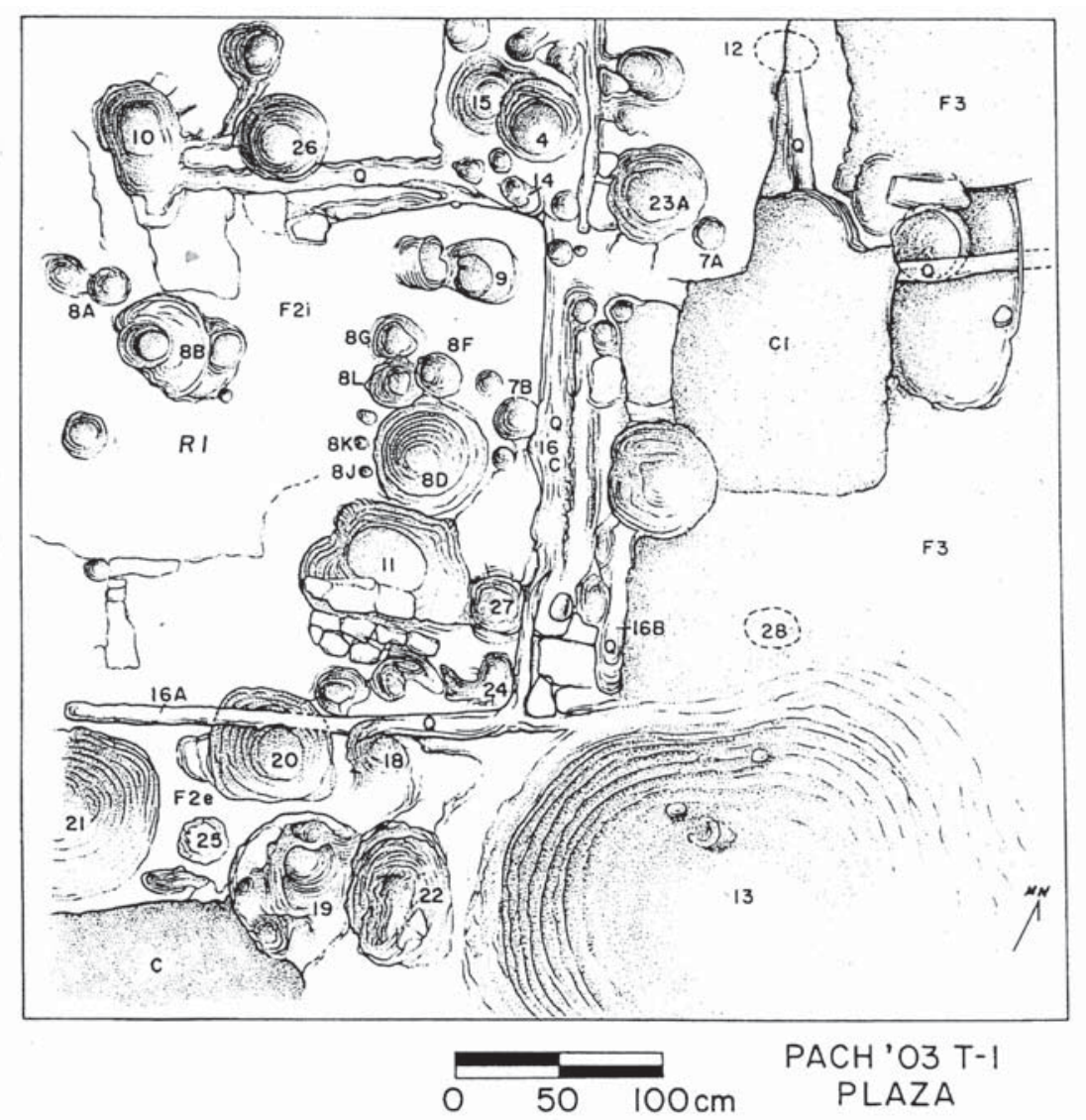

Fig. 5 - Plano 1 de la Trinchera 1 en la Plaza de Los Peregrinos señalando arquitectura y rasgos de la parte tardía del Periodo de Intermedio Tardío (Ychsma

Tardío). Leyendas: $\mathrm{A}=$ adobe; $\mathrm{B}=$ entierro; $\mathrm{C}=$ corte intrusivo; $\mathrm{F}=$ piso; $\mathbf{Q}=$ huella de quincha; $R=$ recinto; $S=$ piedra; $S h=$ fragmento de cerámica; $W=$ muro de adobe; Números arábicos consecutivos = rasgos. Dibujado por Izumi Shimada y César Samillán.

refacciones del enlucido y las capas de relleno. Nueve de dichos pisos presentaron una perfecta superposición secuencial. Además se registraron numerosos rasgos asociados (57 en total) y varias edificaciones de quincha y adobe también superpuestas. En general, a juzgar por los recientes fechados radiocarbónicos que hemos obtenido, los restos enterrados en la Plaza de Los Peregrinos se extienden entre la parte final del Horizonte Medio y las postrimerías del Horizonte Tardío.

\section{3. Secuencia y naturaleza de ocupación en la Trinchera 1}

La superficie actual de la plaza consiste de una capa delgada de arena (circa $5 \mathrm{~cm}$ de grosor) que contiene pocos artefactos y restos diversos. Inmediatamente debajo se 
extiende una superficie compactada y delgada (menos de $5 \mathrm{~cm}$ de espesor) de cantos rodados mezclados en una matriz de arcilla. Esta superficie articula la base de la plataforma del Ushnu inca (en el lado sur de la plaza) con la calzada de las pilastras (que atraviesa longitudinalmente la parte central de la plaza). Tal asociación nos conduce a inferir que esta segunda capa corresponde al apisonado inca de la plaza, lo que se refuerza con la presencia de artefactos y rasgos de contextos primarios diagnósticos. La capa de arcilla y cantos rodados se sobrepone a su vez sobre un grueso relleno de arena de 30 a $40 \mathrm{~cm}$ de grosor. Considerando su origen no local y su tamaño y distribución uniforme, inferimos que los cantos rodados fueron traídos durante la ocupación inca del sitio desde la playa y/o el lecho del río Lurín.

En esencia, la gruesa capa de arena que hemos mencionado enterró las ocupaciones Ychsma pre-inca, y proporcionó un cimiento limpio para la construcción del piso de la plaza y la extensión de la capa de arcilla y cantos rodados. Evidencia similar fue hallada por Julio C. Tello y reportada en un breve artículo periodístico dando cuenta de sus trabajos en la mitad oeste de la Plaza de Los Peregrinos (Tello, 1940). La práctica de extender una capa de arcilla con cantos rodados a modo de piso sobre una gruesa capa de arena limpia fue un hábito extendido entre los incas al momento de construir las plazas de sus centros más importantes, tal como ocurre en Huánuco Pampa (Hyslop, 1990; Craig Morris: comunicación personal, 2004).

Es bastante claro que existe un notable cambio ocupacional debajo del piso de la plaza inca, pues hemos encontrado más de un metro de construcciones de quincha y superficies ocupacionales superpuestas, todas ellas asociadas con abundantes rasgos, restos de producción textil y desechos orgánicos. La presencia de áreas con pupas de gusanos otorgaron la impresión inicial de que estábamos delante de un basural convencional. La asociación constante con cerámica de estilo Ychsma y los resultados de dos recientes fechados radiocarbónicos (Cuadro 1) señalan que dos de estos niveles (Figs. 5 y 6) estaban en uso durante una fase tardía del periodo Ychsma en el sitio (1300 -1450 y $1300-1430$ A.D [según los fechados $540 \pm 60$ y $570 \pm 50$ BP calibrados a 2 sigmas de las muestras Beta-184646 y 184647 respectivamente]). En general, la densidad de desechos y rasgos no deja ninguna duda de que las ocupaciones de este periodo fueron claramente intensivas.

La cantidad de hoyos intrusivos registrados ha sido tal que el tránsito dentro de nuestra trinchera fue sumamente difícil para realizar nuestro trabajo. De hecho, algunos hoyos conservaron las marcas de los cortes de cuatro a cinco hoyos sucesivos hechos sobre el mismo lugar. De forma similar, las paredes de quincha que demarcaron recintos rectangulares en la mitad oeste de la trinchera fueron reiteradamente construidas unas sobre otras (Figs. 5 y 6). Significativamente debemos llamar la atención sobre el hecho de que estos muros mantuvieron esencialmente las mismas orientaciones, ubicación y dimensiones (aproximadamente 30 grados al oeste del norte magnético y de 2,5 a 3,2 m de lado).

La presencia de hoyos de poste señala que al menos ciertas partes de los espacios estuvieron techados. Los hoyos de poste pudieron ser diferenciados del resto de hoyos gracias a su diámetro relativamente pequeño, considerable profundidad, forma cilíndrica y, en algunos casos, debido a los restos de postes e improntas de madera preservadas en la arcilla que revestía los hoyos. 
Cuadro 1 - Fechados radiocarbónicos de algunos niveles de la Trinchera 1.

\begin{tabular}{|c|c|c|}
\hline $\begin{array}{l}\mathbf{N}^{\circ} \text { de Beta } \\
\text { Analítico }\end{array}$ & Fechados & Contextos y afiliación cultural \\
\hline 184644 & $\begin{array}{l}950 \pm 50 \mathrm{BP}(\mathrm{AD} 1000-1200 ; \\
2 \text { sigmas) }\end{array}$ & $\begin{array}{l}\text { Fogón (Rasgo 51), Piso 7, T-1, } \\
\text { Plaza de Perigrinos; Pachacamac-Tardío } \\
\text { Ychsma Temprano transitorio }\end{array}$ \\
\hline 184645 & $\begin{array}{l}560 \pm 80 \mathrm{BP}(\mathrm{AD} 1280-1460 ; \\
2 \text { sigmas })\end{array}$ & $\begin{array}{l}\text { Fogón (Rasgo 56C), Piso 5, T-1, } 2 \\
\text { Plaza de Perigrinos; Ychsma Medio }\end{array}$ \\
\hline 184646 & $\begin{array}{l}540 \pm 60 \mathrm{BP}(\mathrm{AD} 1300-1450 ; \\
2 \text { sigmas) }\end{array}$ & $\begin{array}{l}\text { Fogón (Rasgo 31), Piso 4B, T-1, } \\
\text { Plaza de Perigrinos; Ychsma Medio- } \\
\text { Tardío }\end{array}$ \\
\hline 184647 & $\begin{array}{l}570 \pm 50 \mathrm{BP}(\mathrm{AD} 1300-1430 \\
2 \text { sigmas })\end{array}$ & $\begin{array}{l}\text { Poste (Rasgo 9), Recinto 1, Piso 1C, } \\
\text { T-1, Plaza de Perigrinos; Ychsma Tardío }\end{array}$ \\
\hline 184648 & $\begin{array}{l}1350 \pm 70 \text { BP (AD 580-790; } \\
2 \text { sigmas) }\end{array}$ & $\begin{array}{l}\text { Barra de madera, Piso 1, T-2, Templo } \\
\text { de Urpay Wachak; Lima Final }\end{array}$ \\
\hline 184649 & $\begin{array}{l}360 \pm 50 \text { BP (AD 1440-1650; } \\
2 \text { sigmas) }\end{array}$ & $\begin{array}{l}\text { Mazorcas de maíz, Rasgo 22A, Piso 5, } \\
\text { T-3; a lo a lo largo de la Calle Norte- } \\
\text { Sur, oeste de la entrada al Sector II; } \\
\text { Immediatamente pre-Inka }\end{array}$ \\
\hline 184650 & $\begin{array}{l}580 \pm 50 \mathrm{BP}(\mathrm{AD} 1290-1430 \\
2 \text { sigmas) }\end{array}$ & $\begin{array}{l}\text { Fogón (Rasgo 19), debajo de piso } 7 \text {, } \\
\text { T-4, pequeño montículo en Sector III; } \\
\text { Ychsma Medio }\end{array}$ \\
\hline
\end{tabular}

Sin embargo, los contextos más comunes fueron los hoyos cónicos que sirvieron como repositorios de vasijas de cerámica o algunas ofrendas. En muchos casos las porciones bajas de las vasijas fueron halladas dentro de los hoyos. La configuración deposicional del contenido de estos hoyos sugiere que luego de la remoción de las vasijas, muchos hoyos fueron usados para depositar ofrendas. Dado que frecuentemente tales ofrendas consistieron de objetos y restos mundanos — lo que incluyó, entre otros contenidos, concentraciones de huesos de pescado, huesos de cuy, moluscos y crustáceos, productos agrícolas y fragmentos de cerámica depositados de manera aislada o mezclados con piedras - nosotros los consideramos inicialmente como basura doméstica. Nuestra errada identificación fue en apariencia reforzada porque muchos hoyos de ofrenda alteraron y destruyeron parcialmente otros anteriores de iguales características. Debe anotarse también que algunas ofrendas fueron excavadas en el relleno que separaba algunos pisos de barro propiamente preparados. 


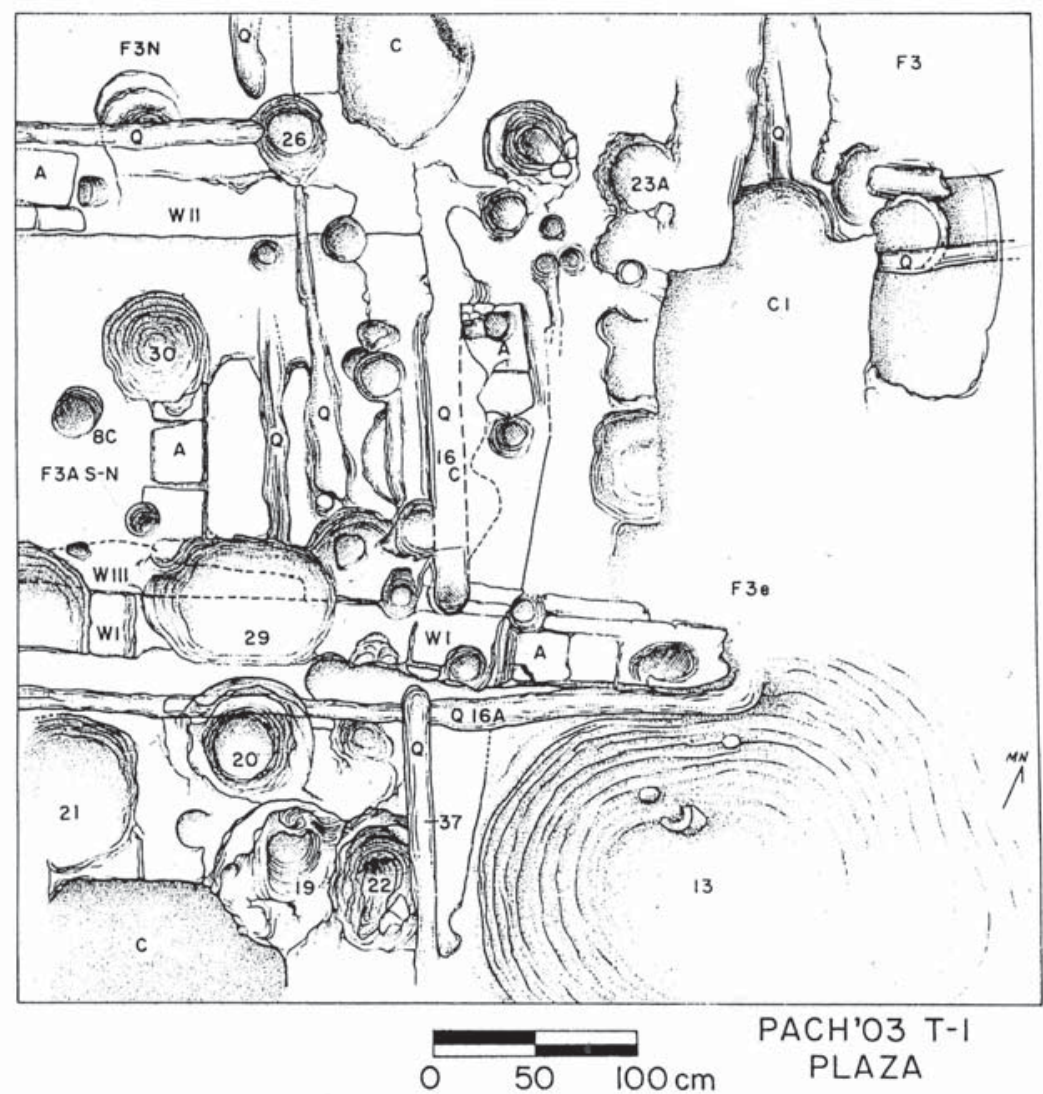

Fig. 6 - Plano 2 de la Trinchera 1 en la Plaza de los Peregrinos señalando arquitectura y rasgos de la parte media del Periodo de Intermedio Tardío (Ychsma Medio). Dibujado por Izumi Shimada y César Samillán.

A pesar de su carácter mundano, estos restos fueron cuidadosamente seleccionados y localizados en los hoyos, dando forma a los contextos que hemos excavado. Por ejemplo, en la mitad oeste de la trinchera fue frecuente el hallazgo de concentraciones de pescados de diferentes especies y tamaños muy bien preservados, al punto de conservar no solo prácticamente la totalidad de su estructura ósea, sino también las escamas todavía intactas. Aparentemente, los pescados quedaron en exposición por algún tiempo, permitiendo que las moscas depositaran sus huevos, según se desprende de la gran cantidad de restos de larvas que hemos hallado. Dentro del contexto de las ofrendas, este hallazgo no parece del todo fortuito si recordamos que existen referencias etnohistóricas que señalan la colocación de ofrendas de anchovetas y sardinas en la plaza principal de Pachacamac (supuestamente la Plaza de los Peregrinos) con el objeto de alimentar y mantener a los buitres y gallinazos cerca del templo, aves éstas que simbolizaban "un aspecto tenebroso de la divinidad" de Pachacamac (Rostworowski, 1992: 47; 2003). 
Las agrupaciones de tiestos de cerámica tampoco reúnen fragmentos provenientes de diferentes partes del cuerpo o de diversos tipos de vasijas al azar. Más bien, las cantidades apreciables de fragmentos de cuerpo, cuellos y bordes de vasijas semejantes (e.g. cántaros y ollas de tamaños similares) fueron reunidas y colocadas juntas dentro de los hoyos, por lo general en la mitad oeste de nuestra excavación. A pesar de que aún queda por determinar si estos fragmentos provienen de vasijas enteras intencionalmente rotas, es evidente que los fragmentos resultantes fueron mezclados y re-agrupados por partes para ser enterrados en áreas debidamente prescritas. Una serie de fragmentos de textiles y de implementos para textilería (e.g. agujas de madera rotas o completas) fue hallada especialmente en el sector noreste de la trinchera.

En suma, una amplia variedad de artículos de subsistencia comúnmente disponibles (e.g., maíz y maní) y artefactos utilitarios asociados con actividades productivas (desde vasijas para cocinar y torteros y agujas para textilería, hasta martillos para trabajar metal) fueron cuidadosamente combinados bajo ciertos parámetros y localizados en diferentes áreas. Es de notar que el patrón de distribución diferencial de diferentes ofrendas persistió casi sin variaciones en el espacio que hemos trabajado a través de los aproximadamente 300 años de ocupación Ychsma.

La presencia de una variedad de artefactos relacionados con la producción artesanal sugiere la existencia de un área cercana de producción actualmente enterrada. En anterior oportunidad la evidencia de producción textil y alfarera ha sido reportada en las Pirámides con Rampa I (de ahora en adelante: PCR) (Jiménez Borja, 1985: 42) y III (Eeckhout, 2003: 147) situadas al noreste de nuestra excavación.

En contraste a aquellos indicadores, creemos que nuestros hallazgos pueden estar relacionados con la preparación de fardos funerarios. La evidencia es más consistente para las actividades textiles, especialmente para las fases de hilado. Además de cierto número de husos y agujas de madera fragmentados ya mencionados, hemos recuperado varios piruros y especialmente una apreciable cantidad de torteros (discos con orificio central que se encajan en el huso) en varios estadios de manufactura. Los torteros fueron hechos de tiestos reciclados de cerámica (especialmente cuerpos de vasijas medianas a grandes) y típicamente midieron de 5 a $7 \mathrm{~cm}$ de diámetro y de 7 a $12 \mathrm{~mm}$ de grosor. Su peso y dimensiones nos sugieren que fueron usados para trabajar hilos relativamente gruesos y burdos. Muchos torteros fueron descartados por defectos o accidentes en su manufactura. Varios fragmentos de tejidos e hilos recuperados nos señalan que la fibra que preferentemente se estaba hilando era el algodón.

Por otro lado, también hemos hallado pequeñas cantidades de cinabrio y pintura ocre en contextos secundarios, así como del interior de algunas conchas bivalvas, y la presencia algo recurrente de yunques y al menos un martillo de piedra (posiblemente diorita) para el trabajo de metal. Cabe señalar sin embargo que la evidencia disponible no permite plantear la existencia cercana de un taller para procesamiento de metal en el área inmediata a nuestra excavación.

Todos estos hallazgos pueden parecer dispares hasta que consideramos el amplio contexto en que se encuentran. Desde nuestro punto de vista es posible establecer relaciones innegables con el tratamiento mortuorio recibido por los miembros de las élites durante este periodo. Muchos entierros han sido huaqueados o excavados 
científicamente en Pachacamac y en otras partes de la costa central (e.g., Kaulicke, 1997). Como se sabe, la mayoría, sino todos los fardos funerarios fueron envueltos con capas consecutivas de telas de algodón, provistos con máscaras de madera pintadas con cinabrio o hechas de tela igualmente pintadas, además de pectorales hechos con láminas de metal diversamente decorados (3). Pensamos que al menos desde le mitad del Periodo Intermedio Tardío hasta fines de este mismo periodo, una parte de esta zona de Pachacamac pudo haber servido como área de soporte laboral de los ambientes de trabajo propiamente dicho y como zona para el descarte ritualizado de los desechos de producción. En cualquier caso, nos parece razonable estimar la cercanía espacial altamente probable de los talleres donde se producían textiles y artefactos de metal, además de otros productos, todos ellos materiales necesarios para las momias de los líderes muertos que se enterraban en el sitio.

Nuestro planteamiento puede ser también relevante considerando la hipótesis formulada por Peter Eckhout (2000), respecto de que las PCR funcionaron como palacios y mausoleos de los señores Ychsma, en modo semejante a las "ciudadelas" Chimú. Esta propuesta induce a preguntarnos acerca del personal y las actividades de servicio de las residencias de élite. Pensamos que las excavaciones fuera de los edificios monumentales amurallados, como las efectuadas en la Plaza de Los Peregrinos, revelarán el otro lado de la moneda: los restos de las actividades cotidianas de la gente que trabajaba para Pachacamac, que ofrendaba a Pachacamac y que servía a sus señores. Creemos que contextos de este tipo, tal como demuestran nuestras excavaciones, se encuentran en varias áreas del sitio y no únicamente concentradas en el amplio sector que se extiende entre la segunda y tercera murallas.

\section{4. Veneración y entierro de cántaros}

Los niveles más profundos alcanzados en la trinchera 1 durante el 2003, que como ya hemos dicho se trata de una profundidad modesta, corresponden a las etapas tempranas del Periodo Intermedio Tardío, alrededor de 1000 - 1100 d.C. (véase Cuadro 1), quizás incluso abarcando la parte terminal del Horizonte Medio. En estos niveles, junto con tiestos Ychsma tempranos frecuentemente decorados con incisiones en el cuello (Fig. 7), recuperamos ocasionales tiestos polícromos de estilo Epigonal (Uhle, 1903; Fig. 8) e incluso fragmentos de cerámica Lima tardíos (Fig. 9) que fueron disturbados por la excavación de los hoyos de ofrendas Ychsma, varios de ellos apreciablemente profundos.

Nuestras excavaciones revelaron que en estos niveles el área abarcada por la trinchera 1 estuvo ocupada por los restos completos o parciales de al menos diez espacios cerrados, correspondientes a pequeñas cercaduras soterradas de forma circular o rectangular ( circa 1,0 a 1,5 m de diámetro o largo máximo) demarcadas por hileras de adobes y/o piedras (Figs. 10-11). Tales cercaduras sirvieron como escenario para lo que

(3) $\mathrm{Al}$ respecto, veáse las fotos de los fardos funerarios de Pachacamac excavados por Uhle (Kaulicke, 2000: Figs. 1-6). 


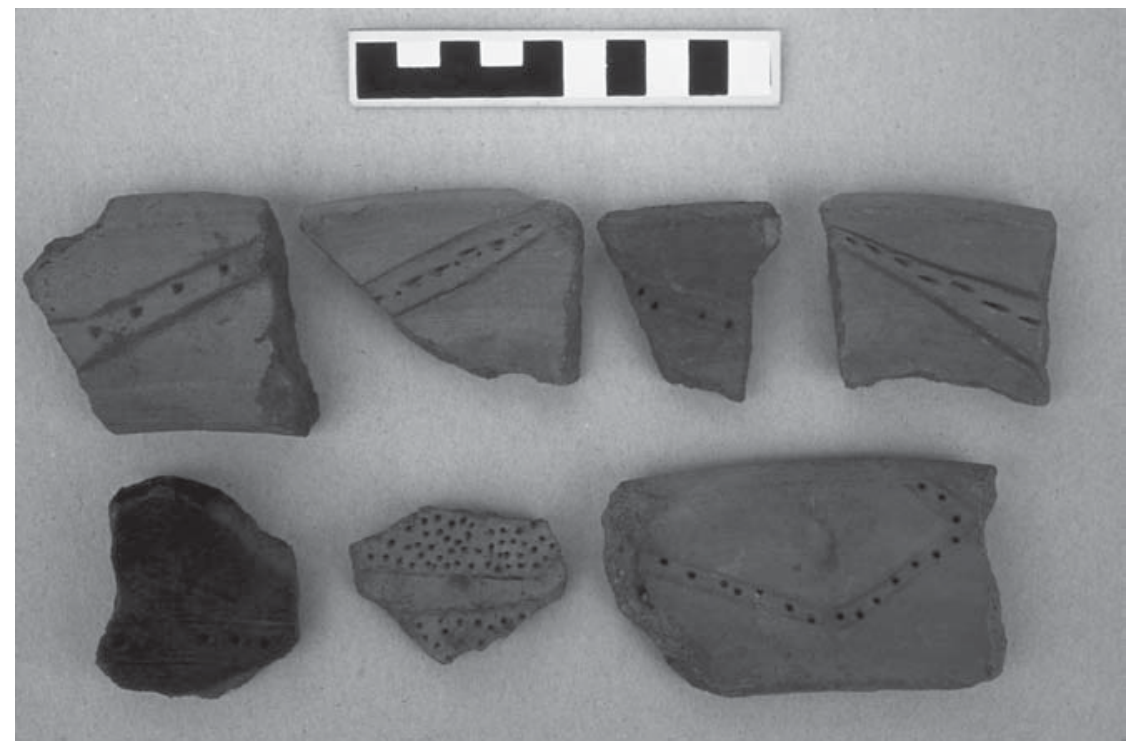

Fig. 7 - Fragmentos de estilo Ychsma con decoración incisa recuperados de la Trinchera 1 en la Plaza de Los Peregrinos. Foto por Izumi Shimada.

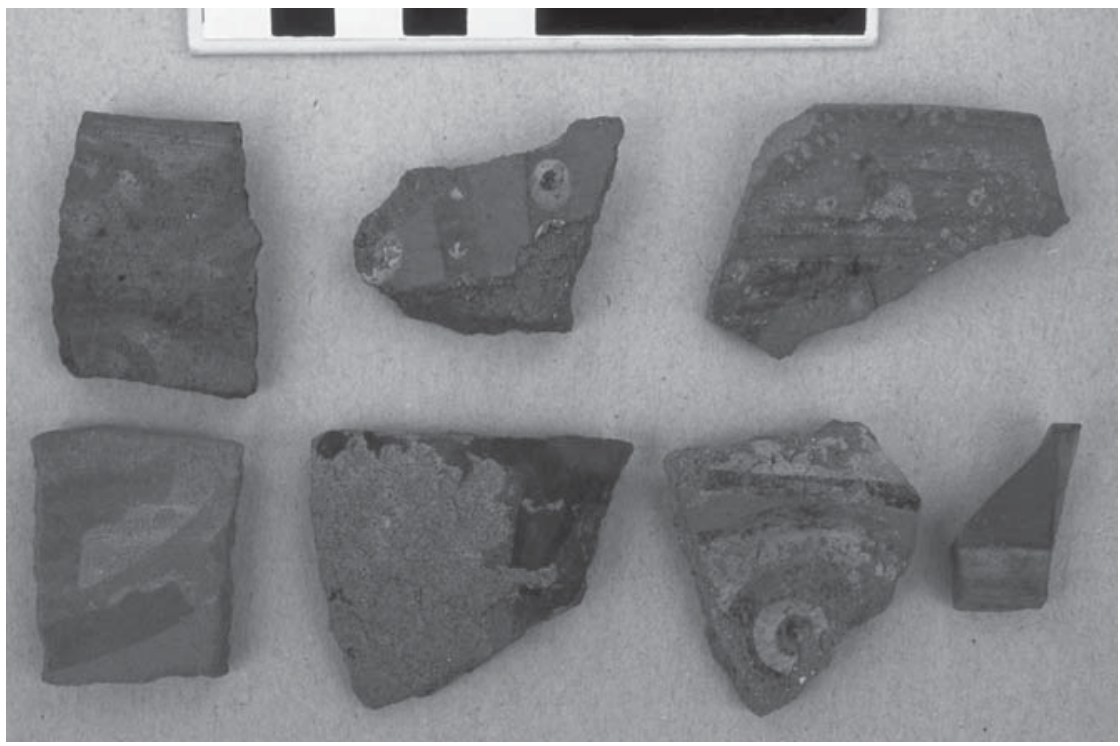

Fig. 8 - Fragmentos de estilo Epigonal recuperados de los niveles inferiores de la Trinchera 1 en la Plaza de Los Peregrinos. Foto por Izumi Shimada. 


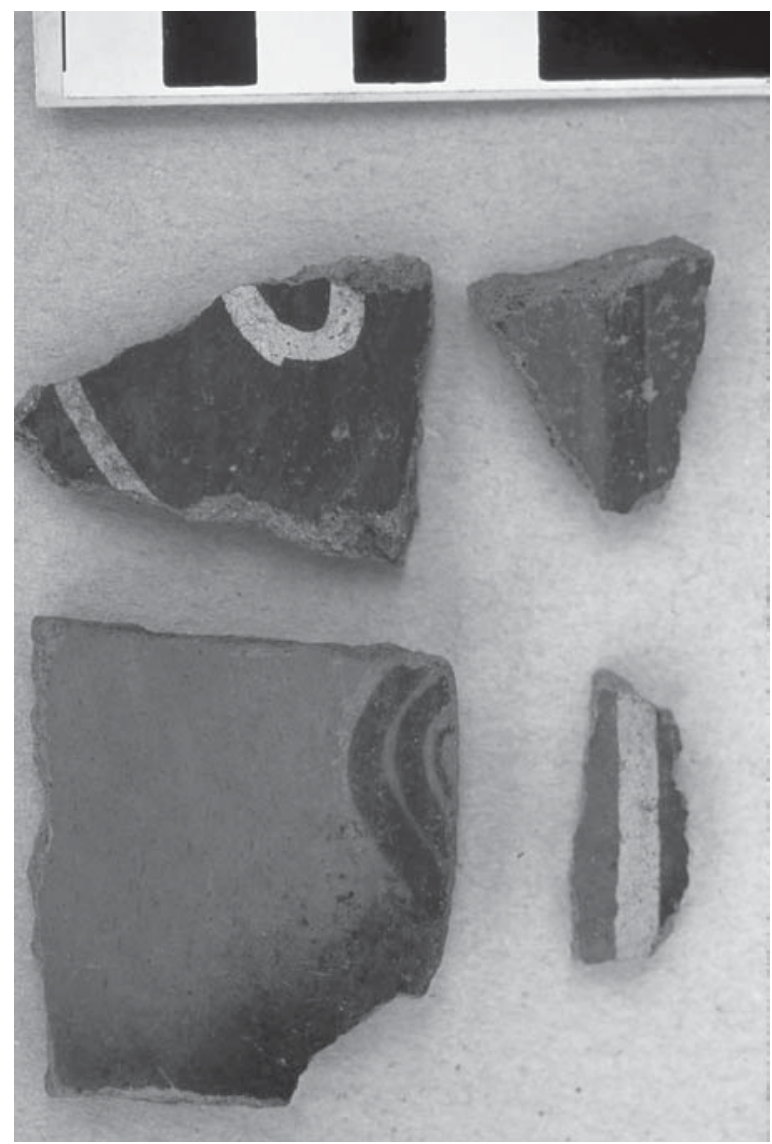

Fig. 9 - Fragmentos de estilo Lima tardío recuperados de los niveles inferiores de la Trinchera 1 en la Plaza de Los Peregrinos. Foto por Izumi Shimada.

nosotros denominamos actividad de "veneración y entierro de cántaros" (4). Todas estas vasijas fueron enterradas de manera especial dentro de los espacios delimitados a modo de cercaduras.

La presencia de una cercadura cerca de la esquina sureste de nuestra trinchera fue detectada tempranamente por las ondas del radar. Allí, dentro del primer metro de excavación, registramos una depresión oval de aproximadamente 1,7 x 2,5 m (Rasgo 13) rellenada con tierra bien consolidada mezclada con tiestos de cerámica y piedras. Tal como se aprecia en las figuras 5, 6,10,11 y 12, este rasgo persistió extendiéndose hacia los niveles inferiores (véase discusión más abajo).

(4) "Cántaros" es un término que, en esta oportunidad, usamos de manera genérica para referirnos a vasijas de almacenamiento generalmente grandes con cuello estrecho y borde divergente. Algunas de ellas, sin embargo, por su forma, tamaño y ocasionales restos de hollín podrían ser catalogadas como ollas. 

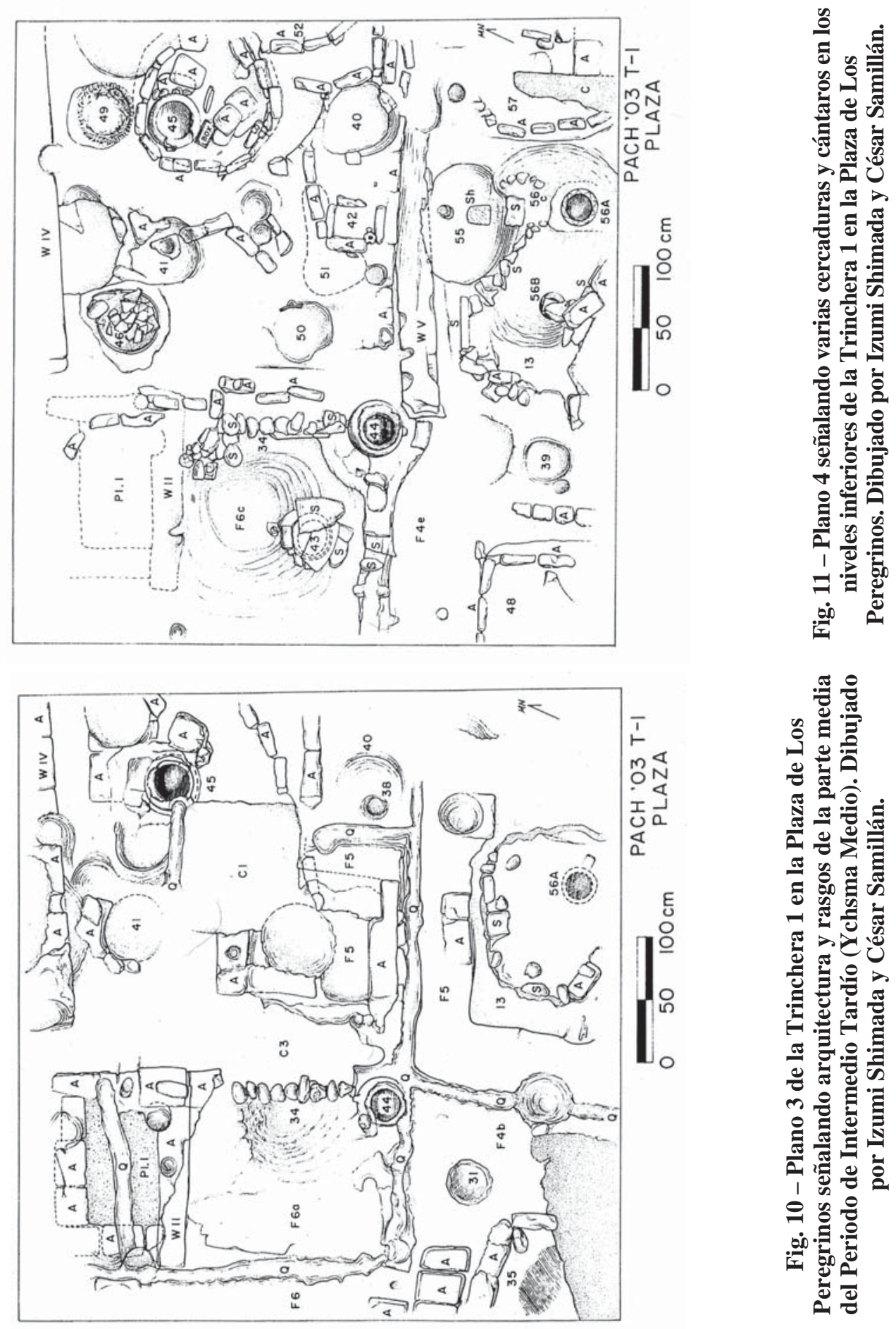


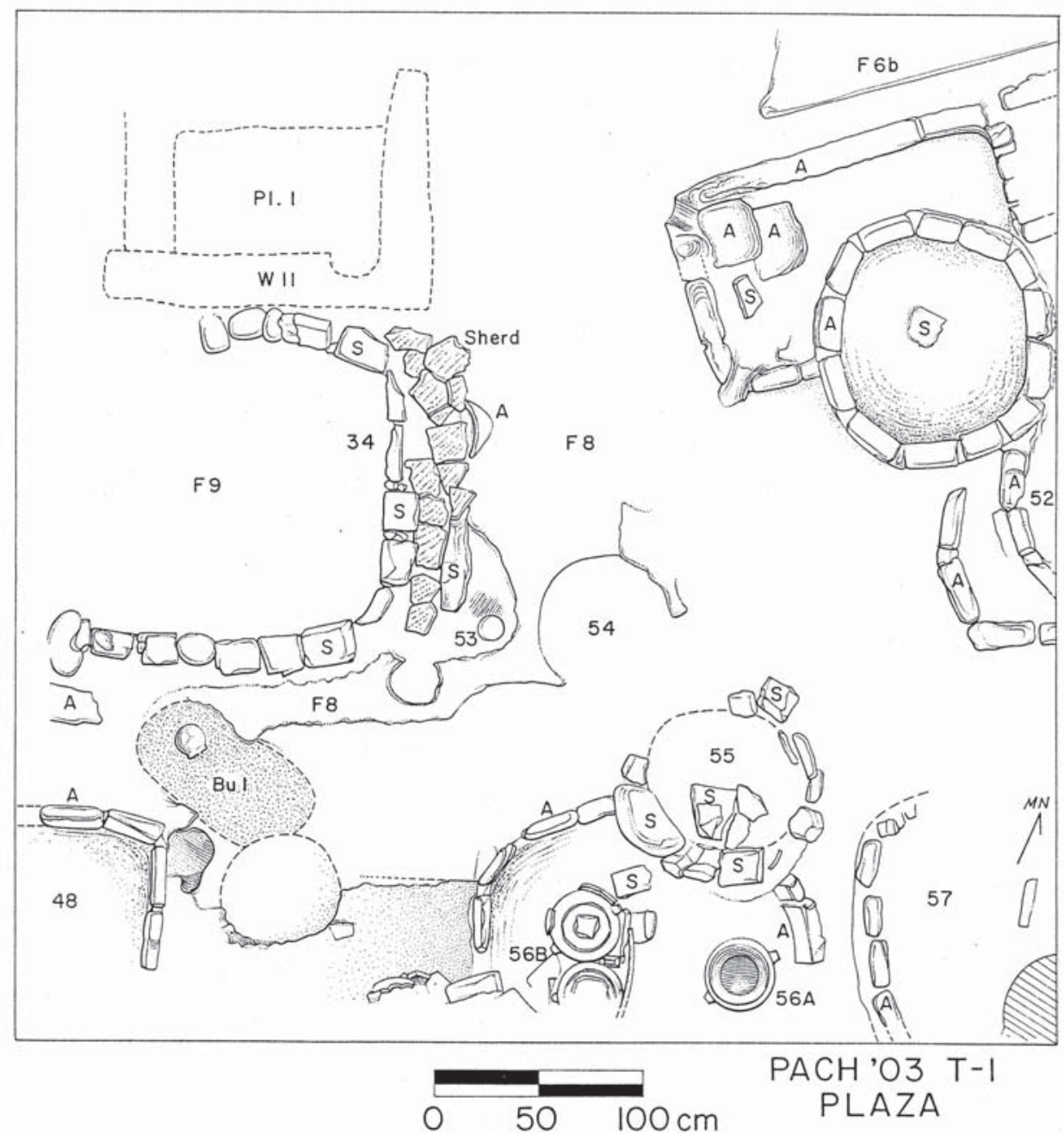

Fig. 12 - Plano 5 señalando varias cercaduras y cántaros en los niveles inferiores de la Trinchera 1 en la Plaza de Los Peregrinos. Dibujado por Izumi Shimada y César Samillán.

El ejemplo mejor conservado de una cercadura circular de adobes conteniendo un cántaro fue el Rasgo 45 ubicado en la esquina noreste de la trinchera. Este contexto ilustra una larga secuencia de actos simbólicos asociados con el entierro de las vasijas (Fig. 13). En primer lugar, es bastante claro que la construcción de la cercadura se inició excavando ligeramente un área circular y luego delimitándola con una hilera de adobes rectangulares (circa 20-22 cm de longitud y $18 \mathrm{~cm}$ de ancho) inusualmente delgados (6-8 cm de grosor), los cuales fueron plantados en forma oblicua, abiertos hacia fuera. Esta estructura se superpuso y dañó al menos dos cercaduras circulares pre-existentes 


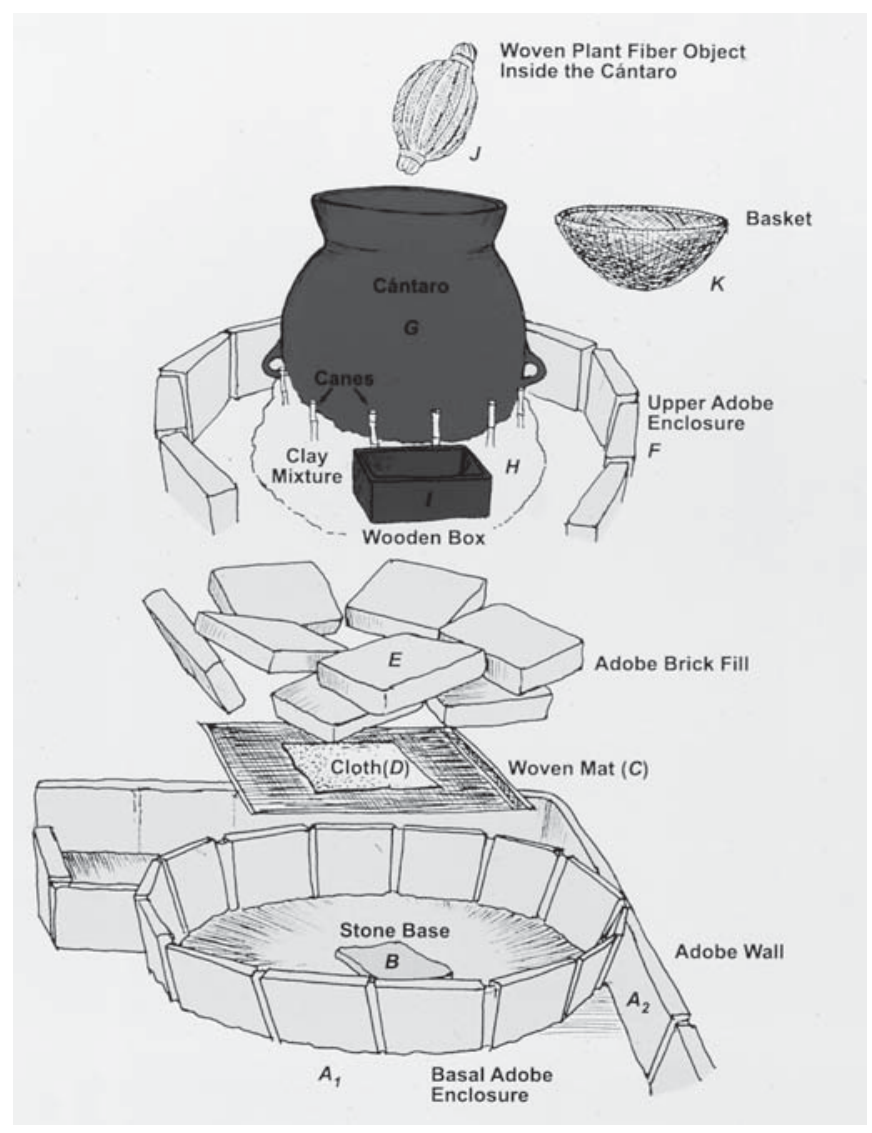

Fig. 13 - Dibujo de reconstrucción presentando la secuencia y los componentes de la "veneración y entierro de cántaros" en el Rasgo 45 de la Trinchera 1. Leyendas: $A_{1}=$ cercadura inferior de adobe; $A_{2}=$ muro de adobe; $B=$ base de piedra tabular;

$C=$ impronta de una esterilla tejida; $D=$ impronta de una tela; $E=$ adobes; $F=$ cercadura superior de adobe; $G=$ cántaro; $H=$ argamasa de barro; $I=$ caja de madera; $J=$ objeto hecho de una serie de fajas tejidas en fibra vegetal; $K=$ una bolsa cónica tejida de fibra vegetal. Dibujado por Izumi Shimada y Steve Muller.

(una de las cuales fue registrada como Rasgo 52). Otra cercadura, esta vez de forma rectangular, adyacente por el lado noroeste (Fig. 12) fue probablemente construida al mismo tiempo que el Rasgo 45, ya que las paredes de ambas cercaduras estuvieron interconectadas con mortero de arcilla. Los adobes empleados en la cercadura circular (Rasgo 45) fueron desbastados por una cara a fin de adelgazarlos y posteriormente colocados oblicuamente con un ángulo hacia fuera de 30 grados con relación a la vertical. El mismo procedimiento de desbastado y colocación oblícua de los adobes fue registrado en otras cercaduras semejantes (Rasgos 48 y 56. Fig. 12). 
La construcción de la cercadura, en el caso del Rasgo 45, continuó con la construcción de un piso de arcilla en el interior y con la localización de una piedra tabular en el centro y a ras de dicho piso. Luego se extendió sobre ella una esterilla tejida y decorada (Fig. 13). Cierta cantidad de adobes y tierra fue colocada encima de todo esto a fin de sustentar el fondo cónico de un cántaro, el mismo que fue asentado en el centro de la cercadura exactamente sobre la piedra y la esterilla. Intermitentemente una serie de cañas fueron colocadas en el relleno para estabilizar los adobes. Otra hilera de adobes, esta vez asentados verticalmente sobre uno de sus lados, fue colocada sobre la primera hilera que hacía de base de la estructura, a la par que una pequeña caja de madera con decoración exterior incisa fue cuidadosamente colocada a un lado del cuerpo de la vasija y enterrada. Luego, más adobes y relleno de tierra fueron depositados hasta alcanzar el cuello del cántaro.

El acto final de esta compleja secuencia de entierro incluyó la localización de una ofrenda dentro de la vasija misma y de una bolsa ("canasta") cónica tejida de fibra vegetal enterrada a un lado y a nivel de la boca del cántaro, pero fuera de la cercadura propiamente dicha. La ofrenda colocada en el interior de la vasija consistió en un objeto de función indeterminada que fue hecho de una serie de fajas tejidas en fibra vegetal y unidas entre sí. Las fajas exhibieron una estructura en zig-zag con los bordes oscuros y más delgados a ambos lados.

El entierro del cántaro descrito representa el ejemplo más elaborado que hemos tenido oportunidad de documentar. En realidad, sospechamos que todo el proceso fue más complejo. Otros ejemplos de entierros son variantes similares del caso que hemos presentado. Por ejemplo, el Rasgo 56A-C corresponde a un contexto que incluyó tres cántaros, dos de los cuales fueron hallados juntos (Rasgos 56B y C) a menos de $50 \mathrm{~cm}$ al oeste del cántaro 56A (Figs. 12, 14). Al mismo tiempo, los cántaros 56B y C tuvieron cada uno un gran tiesto cubriendo sus bocas, además de otros tiestos similares y de piedras tabulares plantadas verticalmente alrededor de las vasijas como si estuvieran protegiéndolas. Estos elementos estuvieron ausentes en el cántaro del Rasgo 56A. Ninguna de estas vasijas tuvieron alguna ofrenda preservada en el interior o exterior, pero las tres estuvieron en el interior de un espacio oval cercado por una pared de adobes rectangulares adelgazados y también plantados oblicuamente sin mortero de barro, en todo similar al Rasgo 45 descrito líneas arriba. Posteriormente la cercadura junto con los cántaros fueron enterrados cuidadosamente.

Algún tiempo más tarde, una nueva cercadura, esta vez más pequeña y hecha a base de piedras y adobes intruyó la cercadura subyacente. Sin embargo, el grupo social que construyó la cercadura oval, o sus descendientes, posteriormente construyeron al menos otras dos cercaduras superpuestas sobre la cercadura original. Más tarde aún, en intervalos difíciles de precisar, al menos siete capas de tierra con alto contenido de arcilla fueron depositadas encima y compactadas. Nuestra prospección con radar había detectado estos rasgos como un todo, pero no los diferenció como cercaduras superpuestas y capas compactadas que, ahora sabemos, representan alrededor de 300 o más años de continuidad.

De igual manera, hemos podido documentar una cercadura rectangular hecha de piedras (Rasgo 34) con un cántaro en su interior, cerca de la esquina noroeste de la 


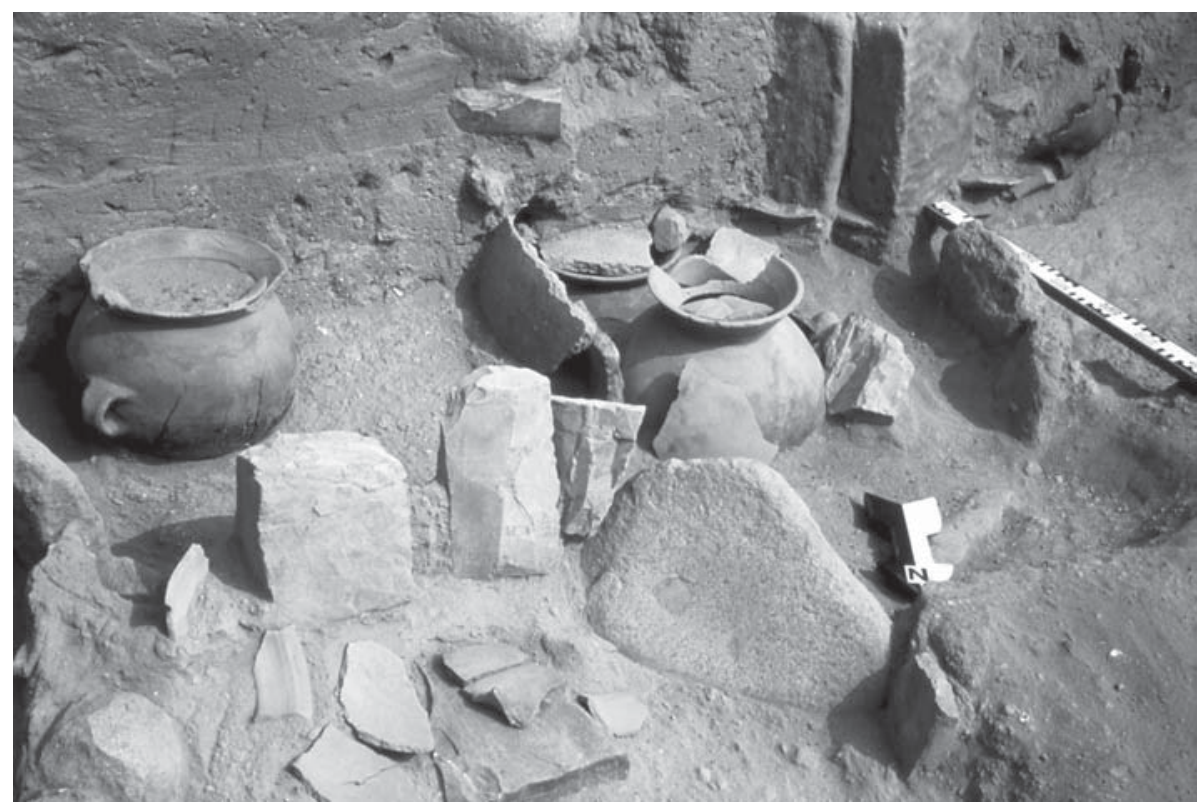

Fig. 14 - Cántaros correspondientes a los Rasgos 56A, B y C, Trinchera 1. Foto por Izumi Shimada.

trinchera, lo que representa otra variación del evento de entierro de cántaros (Figs. 1012, y 15). Dicha cercadura fue construida sobre un piso nivelado a 1,80 m debajo de la superficie actual, usando básicamente piedras de cerro de la zona y grandes cantos rodados. Un bloque de piedra, el más alto entre todos, se ubica en el centro de la pared este de la cercadura y presenta en una de sus caras 16 hoyos grabados de igual tamaño y uniformemente distanciados en hileras, de forma muy semejante a una piedra localizada entre los dos cántaros del Rasgo 56 (Rasgos 56B y C. Fig. 16). Bordeando la cima de la pared este del Rasgo 34 se hallaron varios tiestos grandes de cerámica. Estos habían sido colocados sobre su cara plana y de tal manera que crearon un piso "pavimentado" que conectaba a su vez con un piso de barro bien preparado que circundaba la cercadura (Piso 8, Fig. 12).

Posteriormente, un gran cántaro con borde divergente fue asentado en forma inclinada sobre el piso interior de esta estructura. Cierta cantidad de piedras y de relleno de tierra con alto contenido orgánico fue depositado cuidadosamente alrededor de la vasija para sustentar su inusual posición, presumiblemente para facilitar el acceso al contenido de la vasija. De hecho, algunas piedras sirvieron como cuñas colocadas a la altura de la parte media del cuerpo del cántaro. A medida que el relleno ganó altura, dos hileras de piedra adicionales fueron colocadas sobre la pared de la cercadura. Luego, material orgánico aún no determinado y pobremente preservado fue localizado en el interior de la vasija. La boca del cántaro fue tapada con dos piedras tabulares lisas que sirvieron como batán y chungo respectivamente (i.e., yunque y mano de piedra para molienda; Fig. 15). 


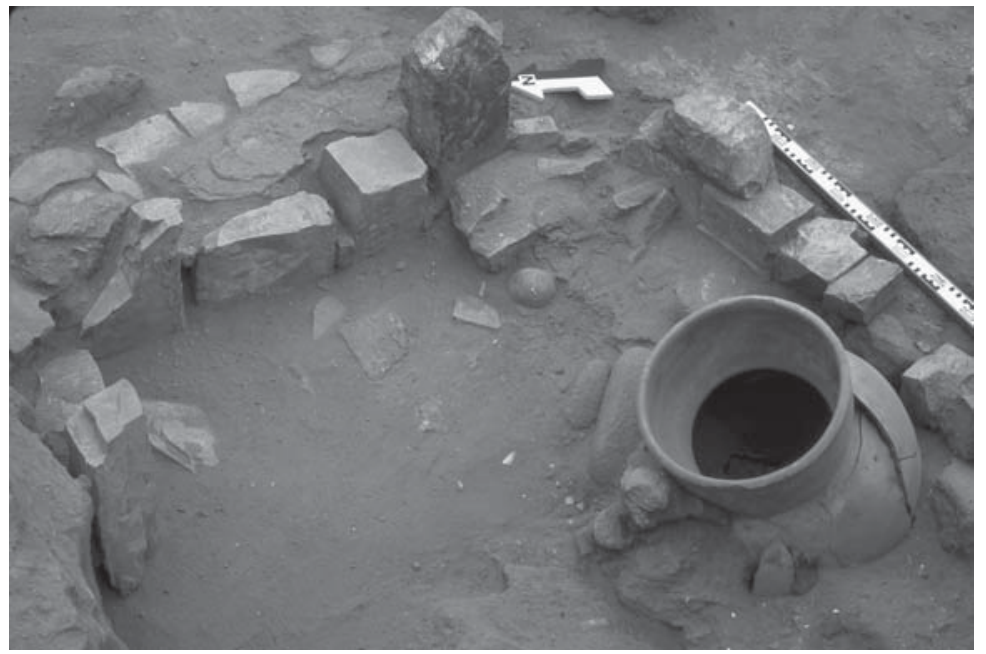

Fig. 15 - Cercadura de piedra y cántaro asociado correspondientes al Rasgo 34, Trinchera 1. Foto por Izumi Shimada.

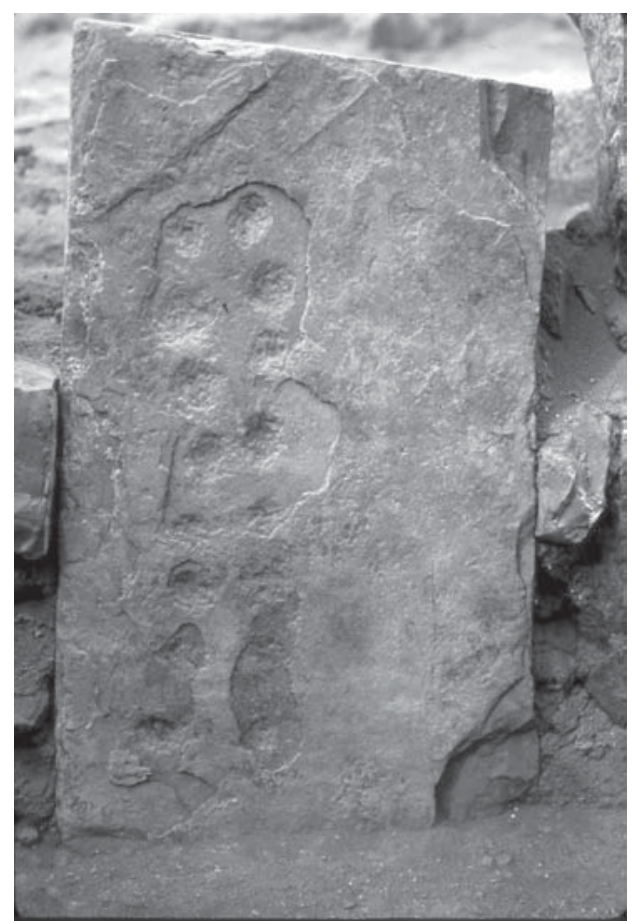

Fig. 16 - Bloque de piedra con depresiones circulares grabadas en hileras. La piedra formó parte de la cercadura que definía el Rasgo 34 en la Trinchera 1. Foto por Izumi Shimada. 
Una pequeña caja de adobe (Rasgo 42), asociada a otra cercadura parcialmente preservada (Figs. 11, 17) con un gran hoyo circular vacío (donde pudo localizarse un cántaro no habido) ofrece otra perspectiva del entierro de cántaros. La caja en mención (con medidas interiores de 32 × 23 × $32 \mathrm{~cm}$ de profundidad) fue cuidadosamente hecha con adobes confeccionados a base de arcilla de grano fino de color amarillo claro y unidos con mortero de barro. Sobre la cima de su esquina suroeste se halló una cabeza de porra de piedra de forma lobulada, y una piedra ovoide pulida que podría haber servido como una bola o piedra de honda. A unos $30 \mathrm{~cm}$ de distancia, fuera de la caja de adobes, se halló también un fragmento de cristal de cuarzo. Creemos que la caja y los objetos de piedra constituyeron una ofrenda hecha a un cántaro enterrado más abajo que nuestras excavaciones no llegaron alcanzar.

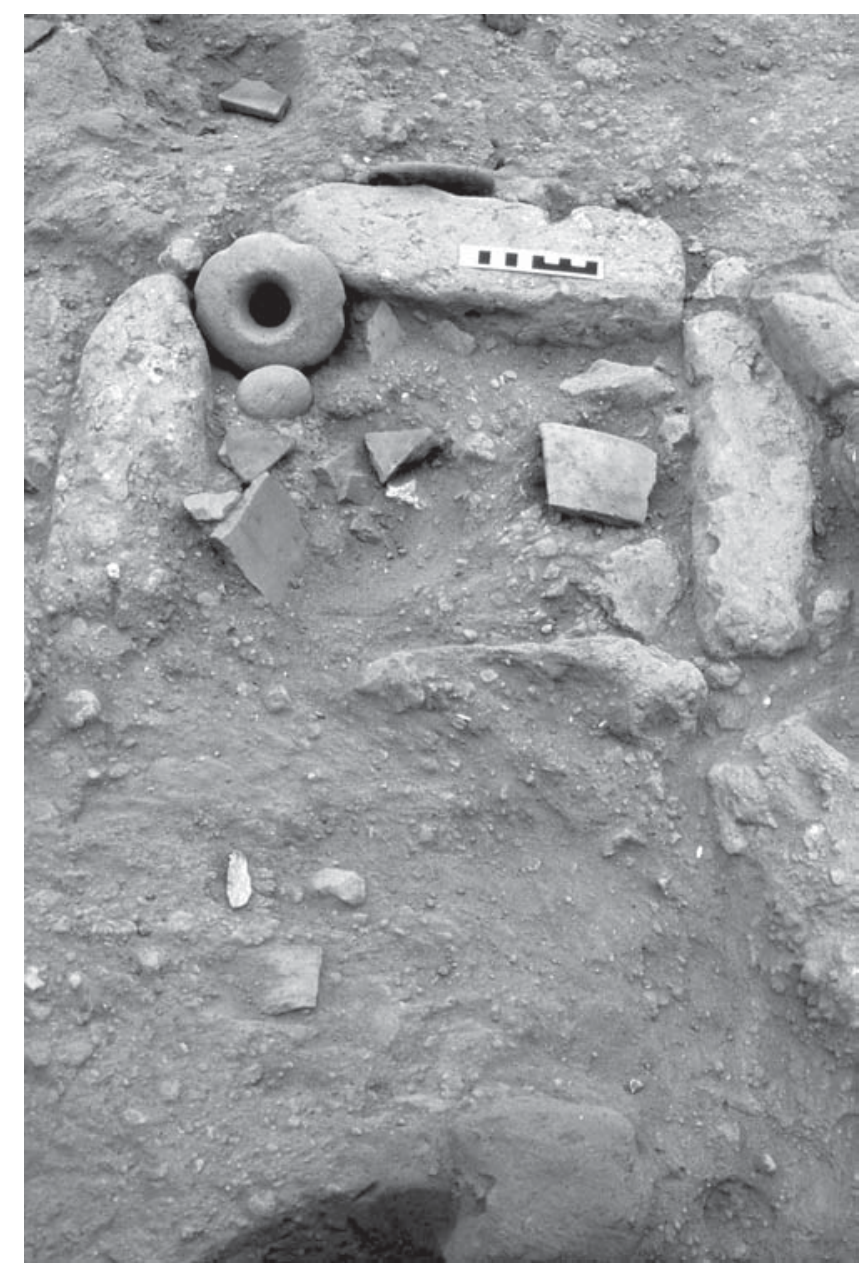

Fig. 17 - Pequeña cercadura de adobe del Rasgo 42, Trinchera 1. Foto por Izumi Shimada. 
La variabilidad observada en el tamaño, forma, materiales y técnicas de construcción de las diez cercaduras excavadas y de los cántaros asociados sugiere que distintos grupos que compartieron ciertas creencias básicas efectuaron estos entierros y su subsecuente cuidado y veneración. La superposición de cercaduras y deposición intencional de capas sucesivas de tierra sugieren que hubo una memoria colectiva social o simbólica notablemente perdurable que vinculó los cántaros y cercaduras en uso con aquellos enterrados, así como una evidente continuidad social o incluso identidad biológica de los individuos que ocuparon o utilizaron el área a través de un considerable espacio de tiempo. A pesar de que aún no hemos iniciado los análisis de la cerámica, cabe considerar la posibilidad de que los tiestos provenientes de los pisos y los cántaros mismos correspondan a distintas fases dentro de la tradición alfarera Ychsma.

Pero ¿cuál fue el significado de los cántaros enterrados? Desconocemos aún su significado simblico preciso, aunque considerando el habitual uso de estas vasijas en la preparación y almacenamiento de chicha, puede sugerirse que habrían desempeñado un rol importante en los ritos propiciatorios o en el culto a los ancestros. Información derivada de las campañas de extirpación de idolatrías durante el siglo XVII nos brinda interpretaciones complementarias y plausibles. Por ejemplo, en 1662, varios testigos en la pequeña comunidad de Mangas, al noreste de Cajatambo en la cabecera del valle de Pativilca, describieron cómo los miembros del ayllu local, Cotos, veneraban y danzaban haciendo ofrendas de plata y otros artículos a un ídolo femenino llamado Coya huarmi, representado por un cántaro cuidadosamente vestido y ataviado (e.g. con collares y cinturones) (Duviols, 1986: 328-344). Se decía que Coya huarmi y su hermano, Condortocas, progenitores del ayllu, habían venido de la costa. Estos y otros testimonios (Duviols, 1986: 328-391) sugieren que en la región de Cajatambo, hubo un amplio culto centrado en cántaros antropomorfizados femenino y masculino, de diferentes tamaños y colores, que representaron a la hermana y hermano primordiales.

Otro documento, también proveniente de la región de Cajatambo y fechado hacia 1662-1663 (Polia, 1999: 503-504) relata una adoración similar de vasijas de cerámica que fueron envueltos en piel de llama o vestidos como mujeres y que sirvieron como oráculos que atendían peticiones y preguntas. Se contaba también que las vasijas realizaban favores de acuerdo a la cantidad de bebida (agua o chicha) mantenida en ellas. En la medida en que las vasijas frecuentemente sirvieron para almacenar agua, también fueron empleadas como objetos especiales en el culto al agua.

El registro etnohistórico mencionado es altamente sugestivo, pero cabe destacar que no contamos en el presente ni con una buena correspondencia entre el tratamiento de los cántaros que hemos registrado arqueológicamente en Pachacamac y los datos históricos, ni con una clara conexión cultural entre la ocupación del Periodo Intermedio Tardío en este sitio y las regiones serranas mencionadas anteriormente. Al mismo tiempo, estos registros etnohistóricos sugieren la amplia distribución del uso prehispánico de vasijas como sustitutos de deidades o de ancestros míticos o reales para aquellos quienes no tuvieron acceso a sus íconos, tumbas o lugares de veneración más prestigiosos. ¿Pudieron los cántaros ser usados de esta manera por aquellos grupos sociales que no tuvieron acceso a los espacios más sagrados del Templo de Pachacamac? 
Como Whitley (2002: 122-123) nos recuerda, “... rites of burial and rites of 'ancestor worship' are ritually and often spatially distinct.” (5) Sea cual fuese la explicación, enfatizamos la posibilidad de que la variabilidad observada en los cántaros, así como en las cercaduras que los contienen y en su tratamiento de entierro, es altamente sugestivo de la coexistencia de varios grupos sociales.

Los cántaros que hemos documentado intruyeron los pisos más profundos de nuestra excavación (circa 1,70 m de debajo de la superficie). Un vaso llano de cerámica tipo kero fue hallado asentado en un corte sobre uno de estos pisos profundos, junto al feto de una llama. Muy cerca, identificamos un entierro de un adulto masculino, el cual fue introducido con cierta dificultad dentro de una fosa pequeña. Su cabeza, que se hallaba desarticulada y que había sido orientada dando cara al Templo de Pachacamac, fue colocada exactamente sobre el cuerpo flexionado y envuelto en una tela desafortunadamente desintegrada. La presencia de dos bordes de matrices correspondientes a dos fosas diferentes sugiere que la fosa original fue abierta en tiempos antiguos para remover la cabeza y colocarla en la posición mencionada. Estos hallazgos, junto con la presencia de algunos tiestos de cerámica de estilo Epigonal, sugieren que nuestra excavación del 2003 se detuvo en niveles correspondientes al final del Horizonte Medio o a un tiempo muy cercano. De hecho, un fechado radiocarbónico obtenido de un fogón asociado a este nivel (Piso 7) nos arrojó un resultado de 1000-1200 A.D (según el fechado $950 \pm 50 \mathrm{BP}$ calibrado a 2 sigmas proveniente de la muestra Beta $-184644)$.

\section{DISCUSIÓN Y CONCLUSIONES}

Resulta evidente que la visión habitual del sitio de Pachacamac ha sido en gran medida modelada por la información etnohistórica y por lo que es visible en el sitio, por ejemplo: fuerte condicionamiento en nuestras interpretaciones por las evidencias prehispánicas de periodos tardíos, omnipresencia de edificaciones monumentales o espacios de naturaleza religiosa para uso de la élite en gran parte del sitio. A pesar de su número y tamaño limitado, las excavaciones de nuestra primera intervención en Pachacamac demuestran que es posible superar visiones parciales, estáticas y simplistas.

Los recientes hallazgos en la Plaza de Los Peregrinos, por ejemplo, ilustran no solo la continuidad e intensidad de la ocupación en el lapso que, por lo menos, va de fines del Horizonte Medio al Horizonte Tardío, sino también su dinámica y carácter cambiante. Entre las varias conclusiones preliminares de nuestras excavaciones al momento realizadas, se pueden señalar en esta oportunidad las siguientes:

1) Como hemos planteado inicialmente, hemos corroborado que debajo de la plaza inca de Los Peregrinos existen numerosos y diversos restos de ocupación prehistórica, superpuestos y consecutivos a través de un espacio de tiempo que se extiende al menos del 600 d.C. (Lima tardío) al 1460 d.C. (Ychsma tardío). Es pertinente anotar que aún cuando la ocupación Lima tardío fue determinada a partir de la presencia de tiestos de cerámica dispersos y algunos segmentos muy destruidos de paredes de adobitos, no procedimos a una

(5) “Con frecuencia los ritos funerarios y los ritos de 'veneración a los ancestros' son ritual y espacialmente distintos." (traducción de los autores) 
investigación detallada de tales restos en la medida que solo alcanzamos estos niveles precisamente al finalizar nuestra temporada del año 2003.

2) La naturaleza del uso del espacio anterior a la construcción de la plaza inca cambió a través del tiempo. Durante la dominación inca del sitio, la plaza parece haber sido un amplio espacio, plano y limpio, subdividido por una calzada con dos filas de pilastras que sigue un eje longitudinal suroeste/ noreste. Durante el predominio Yschma del sitio, el mismo espacio parece haber sido dividido en áreas funcionalmente diferentes, cada una con un tipo de arquitectura, extensión y densidad particulares. Estas ocupaciones preYchsma quedan aún por ser definidas.

3) Durante la ocupación Ychsma, la porción de la plaza que se extiende frente a la plataforma del Ushnu inca (lado norte) fue escenario de intensos y continuos eventos de deposición de ofrendas, focalizados especialmente en el "entierro y veneración de cántaros". Tales cántaros fueron localizados dentro de espacios soterrados circulares, ovales o rectangulares, y delimitados por cercaduras de adobes y/o piedras. La extensión espacial de estos usos rituales también son tarea por enfrentarse en el futuro, aunque los datos de nuestra prospección por radar sugieren que se trata de un espacio confinado a la porción central de la mitad este de la plaza.

4) Las ofrendas tipo hoyos o concentraciones de restos diversos fueron espacialmente diferenciadas, ya sea agrupándolas en la cima o alrededor de las cercaduras subyacentes.

5) La diferenciación espacial y agrupación de ofrendas presentó una fuerte continuidad a través del tiempo, sugiriendo que cada agrupación puede representar efectos acumulados de ofrendas y otras actividades rituales realizadas a través de varias generaciones por un grupo social o étnico específico.

6) Los daños parciales o incluso la casi completa destrucción de muchas cercaduras y ofrendas más tempranas fue el resultado de la construcción de contextos similares posteriores, lo que sugiere enfáticamente que el proceso de la ejecución del ritual (incluyendo la construcción de las cercaduras) fue más importante que lo ofrecido, enterrado o construido.

7) La naturaleza de las ofrendas documentadas se encuentra básicamente relacionadas con la subsistencia básica (pesca y agricultura) y con otras actividades productivas (e.g., textilería de algodón).

8) Dada la frecuencia de alimentos que fueron dejados expuestos a la intemperie, el área puede haber tenido una condición especial en términos de salubridad, maloliente e infestado de moscas durante los meses de verano.

9) Hay indicios que sugieren que pudieron haber existido no muy lejos del lugar de las ofrendas talleres de textilería o para trabajo del metal, los cuales produjeron los artículos necesarios para la preparación de fardos funerarios. De hecho, parte del mismo espacio puede haber sido usado para entierros de la élite. 
Cabe recordar, con relación al punto 6 , el hecho reconocido de que la sustancia real de las ofrendas que se hacen y la participación propiamente dicha en los rituales asociados (incluyendo experiencias sensoriales y corporales) se encuentran estrechamente vinculadas, y por lo tanto definen de manera crucial el verdadero significado de las ofrendas mismas (p.e. Turner, 1969; Pfaffenberger, 2001). Esta perspectiva puede ayudarnos a comprender la lógica cultural que subyace a la construcción y superposición repetida de las cercaduras documentadas, especialmente de los Rasgos 13 y 45. Si bien esta actividad de construcción repetida dañó o destruyó las cercaduras y ofrendas más tempranas, también sirvió para renovar el espacio y poder sagrados que las cercaduras y los cántaros asociados representaban, y en esa medida validar los lazos espirituales de los participantes en el ritual. En este sentido, creemos que las creencias que subyacen a la renovación de las cercaduras, tal como ha sido documentada en la Plaza de Los Peregrinos, pueden muy bien ser similares a, o derivados de, la antigua y ampliamente distribuida (tanto en la costa como en la sierra) tradición de "entierro ritual de templos", iniciada en tiempos del Precerámico tardío (p.e. Burger \& Salazar-Burger, 1980; Izumi \& Terada, 1972; Shady \& López, 2003). La hipótesis es razonable tomando en cuenta que los seis episodios de renovación arquitectónica documentada en la Huaca de La Luna en el valle de Moche presentan que esta tradición de entierro masivo de estructuras y frisos más antiguos persistió al menos hasta el siglo VII d.C. (Uceda, 2001: 58-62) y que en el Montículo II de Huaca Soledad en el Complejo de Batán Grande, valle de La Leche, los cuatro templos superpuestos que lo componen, cada uno de los cuales fue enterrado con un relleno artificial cuidadosamente preparado que incluyó capas de hojas de algarrobo (Prosopis pallida) (Shimada, 1986: 173-175), abarcan en conjunto un lapso que va del Periodo Intermedio Temprano al Horizonte Tardío. Los ejemplos ciertamente pueden multiplicarse, lo que demuestra una continuidad cultural que al menos en sus rasgos más saltantes parece difícilmente rebatible. Postulamos por ello, y a manera de hipótesis, que los conceptos subyacentes al entierro ritual de templos y al entierro de cántaros pudieron contener el mismo interés básico en renovar y reforzar la conexión simbólica entre la población y sus "huacas" sagradas.

Similarmente, el uso de piedras sin modificación alguna o de fragmentos de cerámica como ofrendas cuestionan nuestra noción etic; es decir, nuestra perspectiva desde fuera del contexto cultural original de las ofrendas rituales. Siguiendo las descripciones históricas que dan cuenta que el acceso al interior del recinto sagrado de Pachacamac estuvo restringido a las élites, y considerando el alto estatus de los entierros que Uhle (1903) excavó en la base del Templo de Pachacamac, podríamos haber esperado el hallazgo de ofrendas de alta calidad y/o extraordinaria naturaleza en nuestra trinchera. Pero tal expectativa no parece ser del todo apropiada. A diferencia del pensamiento occidental moderno que considera los objetos, tales como las piedras de campo y los tiestos de cerámica, como elementos inanimados que existen por sí mismos; los pueblos prehispánicos que depositaron estos restos frente al Templo de Pachacamac pueden haberlos considerado como poseedores de alguna forma de espíritu o fuerza vital, y por consiguiente pudieron haber interactuado con ellos de una manera especial. Bajo este razonamiento y dentro del contexto de los eventos rituales, parece oportuno considerar algunas ideas de Walker (2001: 88), quien nos advierte que 
"For impractical objects, ... what they mean is far more important than what they do."

No cabe duda pues que el significado cultural de las ofrendas que nosotros hemos documentado se entienden mejor en su propio contexto social y ritual. Postulamos por ello la hipótesis de que los cántaros y sus espacios cercados (i.e. huacas) simbolizaron ancestros míticos o reales, y que su mantenimiento, a través del ofrecimiento de nuevas ofrendas y de la renovación de cercaduras, sirvió para definir y reforzar la identidad y cohesión de los grupos sociales involucrados. Si la tradición de entierro y veneración de cántaros fue realizada únicamente durante el período Ychsma en Pachacamac, o si empezó en una época anterior, es un tema que queda por ser evaluado. De igual manera, queda en espera la clarificación de si esta práctica incluyó solo a aquellos grupos sociales que no tuvieron acceso a las áreas fúnebres de sus ancestros y/o a los templos. Por el momento nuestra hipótesis de que el entierro y la veneración de cántaros, así como la renovación de las cercaduras asociadas, fueron realizadas por diferentes grupos sociales provenientes de distintos lugares, viene siendo examinada mediante dos procedimientos cruzados: análisis de activación de neutrones de fragmentos de diferentes cántaros y análisis de las diatomeas contenidas en los diversos adobes usados en la construcción de cercaduras y muros asociados.

En suma, a pesar de la extensión limitada de nuestra excavación durante el año 2003 en la Plaza de Los Peregrinos, creemos haber demostrado la importancia del muestreo en zonas no monumentales que tradicionalmente no han recibido mucha atención dentro del sitio, haciendo uso de una visión dinámica y diacrónica en pro de caracterizar la naturaleza y variabilidad de la ocupación humana de Pachacamac.

\section{Agradecimientos}

Nuestro trabajo de campo fue autorizado mediante Resolución Directoral № 00166 del Instituto Nacional de Cultura y sustentado financieramente por la National Science Foundation (BCS-0313964), National Geographic Society (Grant 7472-03), y Heinz Family Foundation. Agradecemos profundamente la participación de todos los miembros del proyecto, peruanos y extranjeros, a los obreros especializados y en particular a nuestros jóvenes arqueólogos Hugo Ikehara, Mónica de la Vega, Alejandra Mendoza y Daniel Saucedo. Go Matsumoto elaboró el plano digital del sitio de Pachacamac que aparece en la Figura 1. El Dr. Hartmut Tschauner tuvo a bien facilitarnos el uso de un GPS de alta precisión para ajuste de medidas en el campo. El Dr. John Jones de la Washington State University (EE.UU) dirigió los trabajos de extracción de sedimentos en la Laguna de Urpay Wachak.

(6) "Respecto de los objetos poco prácticos... es mucho más importante su significado que su empleo utilitario." (traducción de los autores) 


\section{Referencias citadas}

BONAVIA, D., 1985 - Mural Painting in Ancient Peru, 224p.; Bloomington: Indiana University Press. Traducido del español por Patricia Lyon.

BURGER, R. L. \& SALAZAR BURGER, L., 1980 - Ritual and Religion at Huaricoto. Archaeology, 33(6): 26-32.

CLARK, A., 1996 - Seeing Beneath the Soil: Prospecting Methods in Archaeology, 192p.; London: Routledge. Segunda edición.

CONYERS, L. B., 2000 - The Use of Ground-Penetrating Radar in Archaeology. In: Radiation in Art and Archaeometry (D.C. Creagh \& D. A. Bradley eds.): 1-14; Amsterdam: Elsevier Science Publishers.

CONYERS, L. B. \& GOODMAN, D., 1997 - Ground-Penetrating Radar: An Introduction for Archaeologists, 232p.; Walnut Creek, CA: Altamira Press.

CORNEJO G., M., 2000 - La Nación Ishma y la Provincia Inka de Pachacámac. Arqueológicas, 24: 149-173; Lima.

DAGGETT, R. E., 1988 - The Pachacamac Studies: 1938-1941. In: Multidisciplinary Studies in Andean Anthropology (Virginia J. Vitzthum, ed.): 13-21; Ann Arbor University of Michigan: Michigan Discussions in Anthropology 8.

DENYS, L. \& DE WOLF, H., 1999 - Diatoms as Indicators of Coastal Paleoenvironments and Relative Sea Level Change. In: The Diatoms: Applications for the Environmental and Earth Sciences (E.F. Stoermer \& J.P. Smol, eds.): 277-297; Cambridge: Cambridge University Press.

DUVIOLS, P., 1986 - Cultura Andina y Represión: procesos y visitas de idolatrías y hechicerías, ixxxvi + 568p.; Cusco: Centro Bartolomé de las Casas.

EECKHOUT,P., 1999-Pachacamac durant l'Intermédiaire récent : Étude d'un site monumental préhispanique de la Côte centrale du Pérou, 504p.; Oxford: BAR International Series 747.

EECKHOUT, P., 2000 - The Palaces of the Lords of Ychsma: An Archaeological Reappraisal of the Function of Pyramids with Ramps at Pachacamac. Revista de Arqueología Americana, 17-19: 217-254; D.F. México: Instituto Panamericano de Geografía e Historia.

EECKHOUT, P., 2003 - Ancient Monuments and Patterns of Power at Pachacamac, Central Coast of Peru. Beiträge zur Allgemeinen und Verglaichenden Archäologie, 23: 139-182; Bonn: KAVA.

ESTETE, M. De, 1985[1534] - Relación del Viaje que Hizo el Señor Capitán Hernando Pizarro por Mandado de su Hermano desde el Pueblo de Caxamarca a Parcama y de Allí a Xauxa. In: Verdadera Relación de la Conquista del Perú y Provincia del Cuzco Llamada Nueva Castilla por Francisco de Xérez. Edición por C. Bravo; Madrid.

HYSLOP, J., 1990 - Inka Settlement Planning, 377p.; Austin: University of Texas Press.

IZUMI, S. \& TERADA, K. (eds.), 1972 -Andes 4: Excavations at Kotosh, 1963 and 1966, 375p.; Tokyo: University of Tokyo Press.

JIMÉNEZ BORJA, A., 1985 - Pachacamac. Boletín de Lima, 7(38): 40-54.

JUGGINS, S. \& CAMERON, N., 1999 - Diatoms and Archaeology. In: The Diatoms: Applications for the Environmental and Earth Sciences (Eugene Stoermer \& John Smol, eds.): 389-401; Cambridge: Cambridge University Press.

KAULICKE, P., 1997 - Contextos Funerarios de Ancón. Esbozo de Una Síntesis Analítica, 123p.; Lima: Pontificia Universidad Católica del Perú.

KAULICKE, P., 2000 - La Sombra de Pachacamac: Huari en la Costa Central. In: Huari y Tiwanaku: Modelos vs. Evidencias, Primera Parte (Peter Kaulicke \& William H. Isbell, eds.): 313-358; Lima: Pontificia Universidad Católica del Perú. Boletín de Arqueología PUCP 4. 
PFAFFENBERGER, B., 2001 - Symbols Do not Create Meanings - Activities Do: Or, Why Symbolic Anthropology Needs the Anthropology of Technology. In: Anthropological Perspectives on Technology (Michael B. Schiffer, ed.): 77-86; Albuquerque: University of New Mexico Press.

POLIA, M., 1999 - La cosmovisión religiosa andina en los documentos inéditos del Archivo Romano de La Compañía de Jesús (1581-1752), 627p.; Lima: Fondo Editorial, Pontificia Universidad Católica del Perú.

ROSTWOROWSKI, M., 1992 - Pachacamac y el Señor de los Milagros: Una Trayectoria Milenaria, 214p.; Lima: Instituto de Estudios Peruanos.

ROSTWOROWSKI, M., 2003 - Peregrinaciones y Procesiones Rituales en los Andes. Journal de la Société des Américanistes, 89(2): 97-123.

SHADY, R. \& LÓPEZ, S., 2003 - Ritual de Enterramiento de Un Recinto en el Sector Residencial A en Caral-Supe. In: La Ciudad Sagrada de Caral-Supe: Los Orígenes de la Civilización Andina y la Formación del Estado Prístino en el Antiguo Perú (Ruth Shady \& Carlos Leyva, eds.): 187-206; Lima: Instituto Nacional de Cultura, Proyecto Especial Arqueológico Caral-Supe.

SHIMADA, I., 1986 - Batán Grande and Cosmological Unity in the Andes. In: Andean Archaeology: Papers in Memory of Clifford Evans (Ramiro Matos, Solveig Turpin \& Herbert H. Eling, eds.): 163-188; Los Angeles: Institute of Archaeology, University of California.

SHIMADA, I., 1991 - Pachacamac Archaeology: Retrospect and Prospect, 66p.; Philadelphia: University Museum Press, University of Pennsylvania.

SHIMADA, I., En prensa, - Pachacamac. In: Enciclopedia Archeologica (Marina Bucchi, ed.); Roma: Instituto della Enciclopedia Italiana.

SHIMADA, I., SEGURA, R., JONES, J., ROSTWOROWSKI, M. \& WATANABE, H., 2003 Pachacamac Archaeological Project: Results of the First Season and Their Implications. Ponencia presentada en la 22da Reunión Anual de la Northeast Conference on Andean Archaeology and Ethnohistory, 1-2 de noviembre; Cambridge: Universidad de Harvard.

TELLO, J. C., - 1940 - Pachacamac. El Comercio, 4 de agosto: 13; Lima.

TURNER, V., 1969 - The Ritual Process: Structure and Anti-Structure, 213p.; Chicago: Aldine Publishing.

UCEDA, S., 2001 - Investigations at Huaca de la Luna, Moche valley: An example of Moche Religious Architecture. In: Moche Art and Archaeology in Ancient Peru (J. Pillsbury, ed.): 46-67; Washington D.C.: National Gallery of Art. Studies in History of Art 63.

UHLE, M., 1903 - Pachacamac: Report of the William Pepper, M. D., LL. D., Peruvian Expedition of 1896, 103p. + 21 p. de láminas; Philadelphia: Department of Archaeology, The University of Pennsylvania. Traducido del alemán por C. Grosse.

WALKER, W. H., 2001 - Ritual Technology in an Extranatural World. In: Anthropological Perspectives on Technology (Michael B. Schiffer, ed.): 87- 105; Albuquerque: University of New Mexico Press.

WHITLEY, J., 2002 - Too Many Ancestors. Antiquity, 76: 119-126. 